\title{
Sensitivity of modal parameters of multi-span bridges to SSI and pier column inelasticity and its implications for FEM model updating
}

\author{
Muhammad Tariq A. Chaudhary ${ }^{\text {a* }}$ (1) \\ a Civil Engineering Department, Kuwait University, Kuwait. E-mail: tariq.chaudhary@ku.edu.kw, mtariqch@hotmail.com \\ * Corresponding author
}

http://dx.doi.org/10.1590/1679-78255895

\begin{abstract}
Modal parameters, determined through forced vibration testing, ambient vibrations or seismic excitations, are central to the structural health monitoring process for bridges. These parameters are used to obtain highfidelity numerical models through FEM model updating by fine-tuning mass, stiffness and boundary conditions and matching the numerical and observed modal parameters. This study investigated sensitivity of modal parameters to changes in boundary conditions (soil-structure interaction effect) and pier column inelasticity (stiffness effect) through more than $\mathbf{4 5 0}$ non-linear dynamic time-history analysis of an ordinary multi-span bridge. The bridge system was founded on shallow foundations in five rock profiles and on pile foundations in five soil profiles and was subjected to 21 seismic ground motions of varying intensity ( 0.036 to $0.61 \mathrm{~g})$. Modal frequencies showed sensitivity to the SSI and pier column inelasticity effects for low and higher levels of seismic excitations respectively. Mode shapes, on the contrary, were insensitive to SSI as well as pier column inelasticity for all levels of seismic excitations.
\end{abstract}

\section{Keywords}

multi-span bridge; modal parameters; soil-structure interaction; pier inelasticity; FEM model updating; reinforced concrete;

\section{Graphical Abstract}

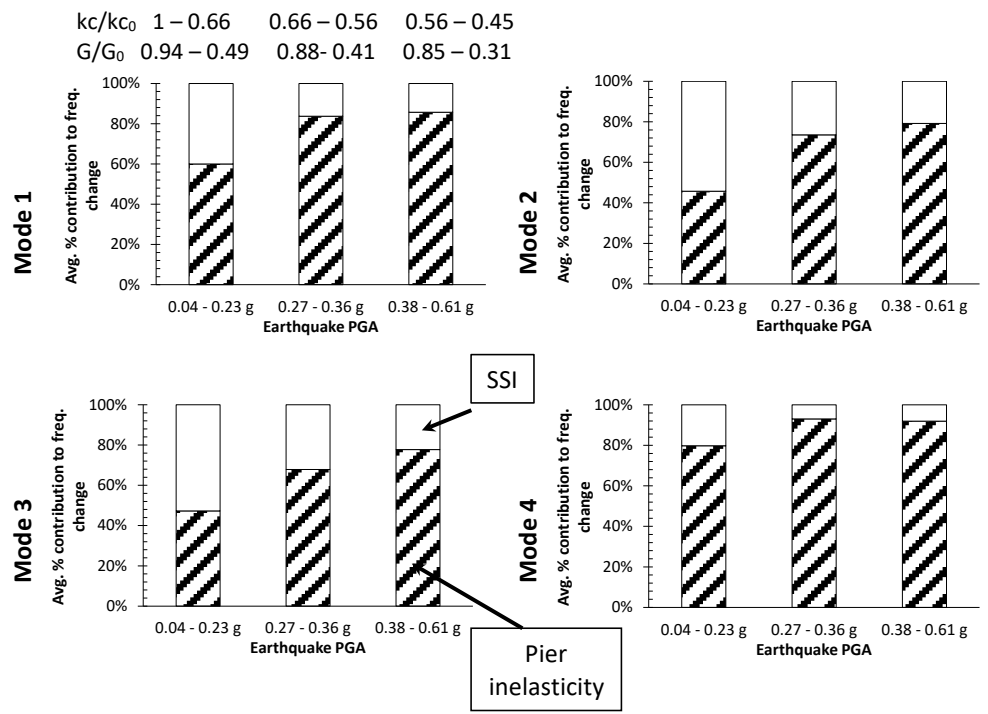




\section{INTRODUCTION}

Structural characteristics of a bridge in the modal domain (i.e. frequency, mode shapes and damping ratio) are the key parameters that can be used to infer structural parameters of a bridge system subjected to forced vibration testing, ambient vibrations or seismic excitations through system identification procedures. Any changes in the system-identified structural parameters from a benchmark value can be interpreted as an indicator of damage of the bridge. This two-step procedure constitutes the basis of Structural Health Monitoring (SHM) of civil infrastructure (Boller et al, 2009). Salawu (1997) provided an early review of use of frequency changes for health monitoring of structural systems while Fan \& Qiao (2011) and Moughty \& Casas (2017) extended the comparison to mode shapes and their curvatures, modal strain energy, operational deflection shapes, flexibility and finite element method (FEM) based methods.

Acquisition of modal data is an involved and expensive process. Therefore, many times, the acquired modal data is utilized to calibrate a FEM numerical model for carrying out parametric studies involving various scenarios of damage or for using it as a benchmark for future testing and evaluation (Friswell \& Mottershead, 2013). This process, termed FEM model updating, is focused mainly around fine-tuning three parameters, i.e. mass, stiffness and boundary conditions. Any error in correctly estimating these parameters can cause variations in modal parameters of the bridge and can impair the SHM process. Sources of error in estimating the correct values of stiffness in a bridge system can arise from deteriorating material strength, local damage (Teughels \& De Roeck, 2004; Dilena \& Morassi, 2011), insitu dimensions and/or strength properties being different than the design values (Costa et al., 2016), environmental factors i.e. temperature and humidity variations (Alampalli, 2000; Xia et al., 2012) and unintentional locking of bridge components (bearings, side stoppers, expansion joints) due to lack of maintenance or fabrication errors etc.(Chaudhary et al. 2002; Maalek et al, 2010). Similarly, soil-structure interaction (SSI) (Fraino et al, 2012; Gomez et al, 2013; Chaudhary 2017a), scour around foundations (Ju, 2013; Bao \& Liu, 2017), support settlement or liquefaction can change the boundary conditions and impact the modal parameters of the bridge system (Catbas \& Aktan, 2002; Lombardi \& Bhattacharya, 2014). Researchers have reported discrepancies between initial and updated structural parameters based on FEM model updating of more than $100 \%$ to get a good match between the recorded and FEM model values of the modal parameters (Ntotsios et al., 2009; Chen et al., 2014).

AASHTO (2017) does not require incorporation of SSI in the analysis and design of ordinary bridges. Inclusion of SSI is, however, encouraged for irregular structures in certain seismic zones. The prevailing view about the beneficial effect of SSI by lengthening the structural period and consequentially resulting in a reduction of seismic demand has been challenged by various researchers (Mylonakis \& Gazetas, 2000; Sextos et al., 2003; Lesgidis et al., 2017), who demonstrated that SSI may not be always beneficial. SSI effect has been researched theoretically (Wolf, 1985), through laboratory experiments (Pitilakis et al., 2008; Sextos et al, 2016; Martakis et al., 2017), field testing and onsite measurements (Kawashima 1980; Chaudhary et al., 2001; Hogan \& Wotherspoon, 2014) and numerical simulations (Spyrakos, 1990; Papadopoulos et al., 2018). Although inclusion of SSI is not required for seismic design, its incorporation and fine-tuning of soil-foundation impedance is one of the important part in the FEM model updating process for reducing error between the values of recorded and numerical FEM modal parameters.

SSI is inter-disciplinary (geotechnical and structures) and past work on the subject reflect bias based on the discipline. Many studies related to the influence of SSI on structural performance assumed elastic, non-degrading superstructure (Vlassis and Spyrakos, 2001; Ouanani \& Tiliouine, 2015) or used foundation choices that were not designed according to the prevailing design practices (Chen \& Lai, 2003; Grange et al., 2011; Ni et al., 2014) and thus accentuated the impact of SSI on structural performance and modal parameters. Other studies considered elaborate models for nonlinear behavior of structural elements but did not include SSI based on the prevailing assumption of beneficial effect of SSI (Kalkan \& Kwong, 2011; Şadan et al., 2013). Studies that included both SSI and inelastic behavior of structural elements had conflicting opinion about the role of SSI. Ciampoli \& Pinto (1995) and Jeremić et al. (2004) indicated that SSI did not had a detrimental effect on non-linear ductility demand of bridge piers founded on shallow and deep foundations respectively. However, Mylonakis et al. (2006a), Kappos \& Sextos (2009) and Zheng et al. (2015) found a non-negligible contribution of SSI towards inelastic structural seismic demand. Chaudhary $(2017 \mathrm{~b}, 2018)$ and Faraonis et al. (2019) noted that impact of SSI on structural performance and modal parameters was related to the relative stiffness of pier columns and soil-foundation system instead of properties of the supporting soil alone.

Focus of this study was to numerically investigate the influence of two parameters that are fundamental to the FEM model updating procedure for multispan bridges i.e. SSI and pier column inelasticity. Effect of these parameters on changes in modal frequencies and mode shapes of ordinary, multi-span highway bridges was investigated herein through a non-linear FEM numerical model. The bridges were founded on shallow foundations in rock profiles (AASHTO site classes A, B and C) and on pile-group foundations in soil profiles (AASHTO site classes C and D) and were subjected to a suite of ground motions varying in peak ground acceleration (PGA) from 0.04 to $0.61 \mathrm{~g}$. Results and conclusions of the 
study delineated the relative importance of SSI and pier column inelasticity on variation in modal properties of the bridges and provided a heuristic guidance for FEM model updating of the type of bridges studied herein.

\section{ADOPTED METHODOLOGY AND ASSUMPTIONS}

\subsection{Adopted Methodology}

Numerical model of an ordinary, standard four-span bridge having medium span length $(30 \mathrm{~m})$ and located in a moderate seismic zone was considered in the study as depicted in Figure 1. Such bridges are extensively used for long, elevated urban highway viaducts in USA, Japan, Europe and other parts of the World. Steps adopted in the study included:

1. Design / Selection of bridge system

An interior 4-span bridge segment from a 4-lane elevated urban viaduct bridge with equal span lengths and no skew was selected and its superstructure, piers and foundation system for various rock and soil profiles were designed for appropriate combinations of dead, live and seismic loads according to AASHTO (2017).

2. Dynamic soil properties and foundation impedance

Representative dynamic soil/rock properties i.e. damping ratio $\left(B_{s}\right)$, shear wave velocity $\left(V_{s}\right)$ and soil shear modulus $\left(G_{s}\right)$ were computed using 1-D seismic site response analysis and were utilized for computing impedance of shallow and pile-group foundations in rock and soil profiles respectively as explained in section 3.

3. Selection of suite of seismic ground motions

Seven seismic ground motions each corresponding to three levels of seismic intensity i.e. Design Basis Earthquakes

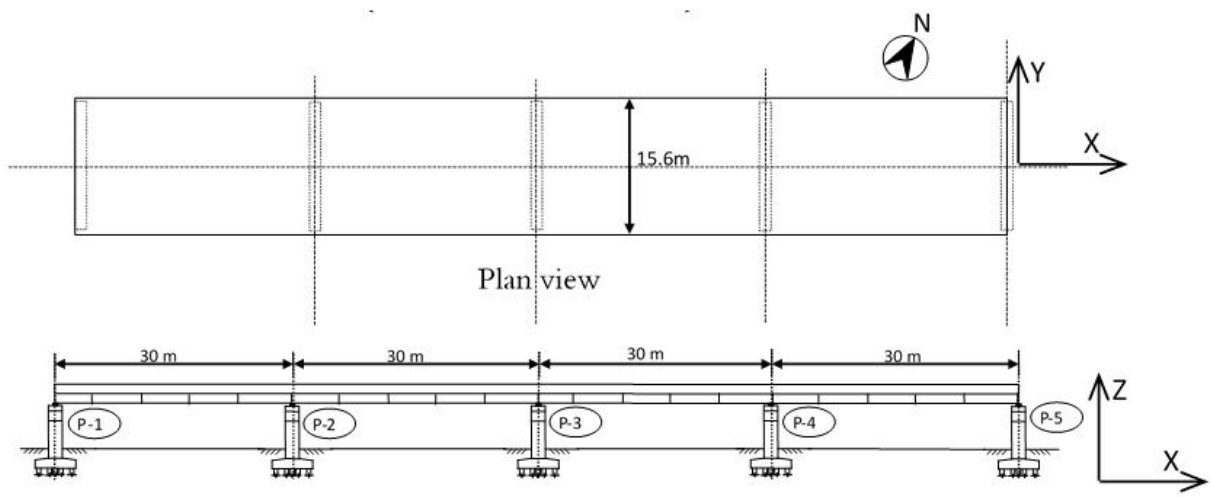

(b) Longitudinal Elevation

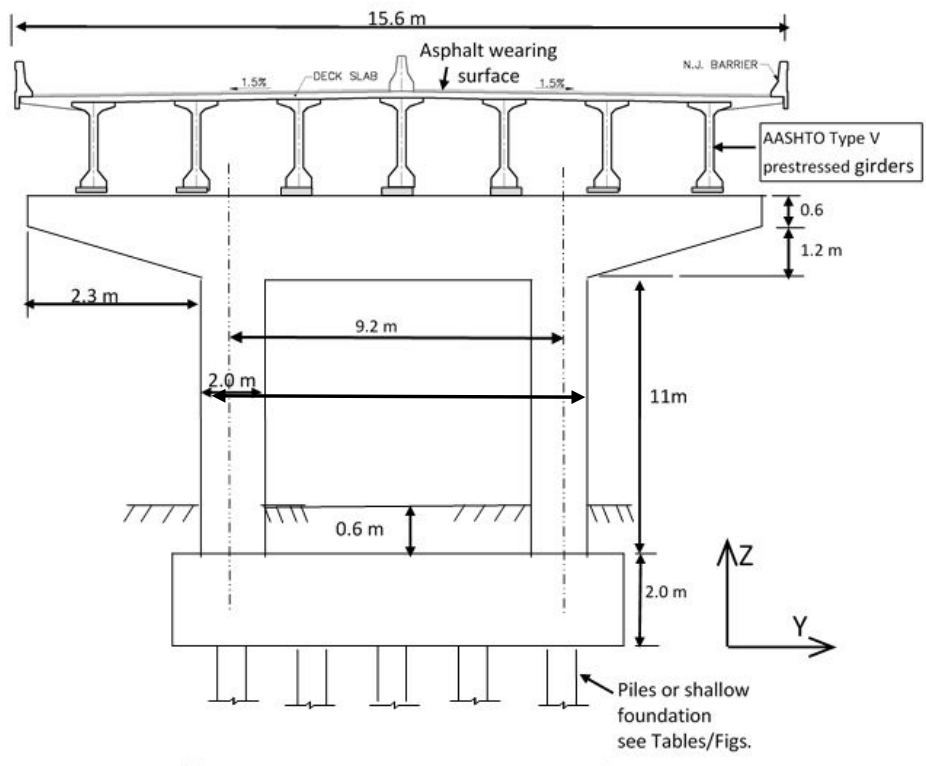

(c) Transverse Cross-Section View of Pier

Figure 1: General arrangement of the bridge 
(DBE), Functional Evaluation Earthquake (FEE) and Maximum Credible Earthquakes (MCE) were selected from the online database of actual earthquakes for a moderate seismic zone with PGA of $0.17 \mathrm{~g}$ as detailed in section 4.

4. Numerical modeling and FEM analysis of bridges

A 3D numerical model of the bridge system was prepared in FEM package SAP2000 (CSI, 2019) and non-linear timehistory analysis was conducted for the selected seismic ground motions for each level of seismicity and site class. Substructuring method was used for incorporating SSI in FEM model of the bridges. Dynamic foundation impedances (i.e. stiffness and damping) were modeled in the 3D FEM numerical model of the bridge as Winkler springs and dashpots as outlined in section 5. Inelastic behavior of the pier columns was captured through plastic hinge elements.

5. Examination of numerically determined modal parameters and sensitivity analysis

Sections $6 \& 7$ present an extensive analysis of changes in modal frequencies and mode shapes to gain an insight on their sensitivity to variations in SSI and pier column inelasticity and their influence on the FEM model updating procedure for the bridge type studied herein.

\subsection{Assumptions}

The following assumptions were made in the study:

a) Effect of abutments were not modeled as an interior portion of the multi-span viaduct was selected for analysis.

b) The bridge did not have any skew, horizontal or vertical curve and was not situated on a gradient. Consequentially, all pier columns were of the same height.

c) The bridge had conventional bearings that did not provide any isolation between the super-structure and the sub-structure.

d) SSI modeling did not include kinematic effects as dominant part of SSI in bridge foundations is due to the inertial interaction effects (Avilés \& Pérez-Rocha, 2003). Furthermore, radiation damping in the foundations was also neglected due to its less significant impact on overall damping in the soil-foundation system (AASHTO 2017; Zhang \& Tang 2006).

e) Seismic wave passage effect was disregarded in the study due to the rather short bridge spans (i.e. $30 \mathrm{~m}$ ).

\section{BRIDGE DESCRIPTION AND DESIGN}

\subsection{Bridge Layout}

Figure 1 depicts the layout and elevation of the $120 \mathrm{~m}$ long, four-span continuous highway bridge used in the study. Bridge deck was $15.6 \mathrm{~m}$ wide to accommodate four lanes of traffic and consisted of $50 \mathrm{~mm}$ asphalt wearing surface laid on $200 \mathrm{~mm}$ reinforced concrete slab supported on AASHTO Type $V$ prestressed concrete girders that were made continuous for live load. Substructure components consisted of a deep pier cap and $11 \mathrm{~m}$ tall two-column reinforced concrete bents that were founded in a rigid shallow foundation and a deep pile cap for the rock and soil profile bridges respectively. Bridge super-structure and sub-structure components were designed according to the load combinations stipulated in the AASHTO code for a moderate seismic zone with PGA of $0.17 \mathrm{~g}$.

\subsection{Bridge Foundations}

AASHTO categorizes site profiles into six categories (A to E) based on shear wave velocity $\left(V_{s}\right)$ in upper $30 \mathrm{~m}$ of the strata. In AASHTO, rock profiles are designated as site classes $A$ and B, soft rock/hard soil profiles as class $C$ and normal profiles as class $D$. Shallow surface spread foundations were designed in AASHTO site classes A and B, whereas deep pile foundations were employed in site classes C and D. CSIR classification (Bieniawski, 1974) was utilized to further divide AASHTO rock sites into five sub-classes as detailed in Table 1. Likewise, AASHTO soil site classes C and D were also split into five sub-profiles as listed in Table 2. Salient mechanical properties of rock and soil profiles used in the study are summarized in Tables 1 and 2 respectively. 
Table 1: Rock profiles used in the study and their low-strain mechanical properties

\begin{tabular}{|c|c|c|c|c|c|c|c|c|c|c|}
\hline \multirow{2}{*}{$\begin{array}{l}\text { CSIR } \\
\text { Rock } \\
\text { Class }\end{array}$} & \multirow{2}{*}{$\begin{array}{c}\text { Rock } \\
\text { Descripti } \\
\text { on }\end{array}$} & \multirow{2}{*}{$\begin{array}{l}\text { AASHTO } \\
\text { Site Class }\end{array}$} & \multirow{2}{*}{$\mathrm{RMR}^{1}$} & $\rho$ & \multirow[b]{2}{*}{$\mathbf{v}$} & $E_{0}$ & $\mathbf{G}_{0}$ & $V_{s}$ & FOS $^{2}$ & $q_{a}$ \\
\hline & & & & $\mathrm{g} / \mathrm{cm}^{3}$ & & $\mathrm{GPa}$ & $\mathrm{GPa}$ & $\mathrm{m} / \mathrm{s}$ & $(\min .2 .5)$ & $\mathrm{kN} / \mathrm{m}^{2}$ \\
\hline 1 & $\begin{array}{l}\text { Very } \\
\text { good }\end{array}$ & A & 85 & 2.9 & 0.15 & 74.99 & 32.60 & 3353 & 2.50 & 3816 \\
\hline II & Good & A & 70 & 2.6 & 0.20 & 31.62 & 13.18 & 2251 & 2.80 & 2051 \\
\hline III & Fair & B & 50 & 2.3 & 0.25 & 10.00 & 4.00 & 1319 & 3.54 & 839 \\
\hline IV & Poor & B & 30 & 2.0 & 0.30 & 3.16 & 1.22 & 780 & 3.98 & 385 \\
\hline V & $\begin{array}{l}\text { Very } \\
\text { Poor }\end{array}$ & C & 17 & 2.03 & 0.35 & 2.02 & 0.74 & 600 & 4.00 & 215 \\
\hline
\end{tabular}

${ }^{1}$ RMR: Rock Mass Rating ${ }^{2} \mathrm{FOS}$ : Factor of Safety

Table 2: Soil profiles and their low-strain mechanical properties

\begin{tabular}{|c|c|c|c|c|c|c|}
\hline AASHTO Site Class & Soil Profile & $V_{s}(m / s)$ & $\rho\left(\mathrm{kg} / \mathrm{m}^{3}\right)$ & $\mathbf{v}$ & $\mathrm{G}_{0}(\mathrm{MPa})$ & $\beta_{0}(\%)$ \\
\hline \multirow[t]{2}{*}{ C } & C_upper & 600 & 2060 & 0.35 & 741 & 3 \\
\hline & C_avg & 475 & 2020 & 0.35 & 456 & 4 \\
\hline \multirow[t]{3}{*}{ D } & D_upper & 350 & 1980 & 0.40 & 243 & 5 \\
\hline & D_avg & 275 & 1900 & 0.40 & 144 & 7 \\
\hline & D_low & 180 & 1850 & 0.42 & 57 & 8 \\
\hline
\end{tabular}

\subsubsection{Dynamic soil/rock properties}

Values of soil/rock parameters $\left(B_{s}, V_{s}\right.$ and $\left.G_{s}\right)$ required for calculating foundation impedance are dependent on soil strain induced in the strata due to the passage of seismic waves. Representative values of these parameters were found from 1-D seismic site response analysis study (Chaudhary, 2016). Median values of these parameters for each level of seismic intensity are reported in Table 3 and were used to determine foundation impedances as explained in the next section.

Table 3: $G / G_{0}$ and $\beta_{s}$ values determined from 1-D site response analysis

\begin{tabular}{|c|c|c|c|c|c|c|c|}
\hline \multirow{2}{*}{\multicolumn{2}{|c|}{ Rock / Soil Type }} & \multicolumn{3}{|c|}{$\mathbf{G} / \mathbf{G}_{0}$} & \multicolumn{3}{|c|}{$\beta_{s}(\%)$} \\
\hline & & DBE & FEE & MCE & DBE & FEE & MCE \\
\hline \multirow{5}{*}{ 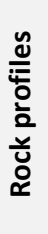 } & Class I & 1.0 & 1.0 & 1.0 & & & \\
\hline & Class II & 1.0 & 1.0 & 1.0 & & & \\
\hline & Class III & 1.0 & 1.0 & 0.98 & & 1.00 & \\
\hline & Class IV & 1.0 & 0.97 & 0.94 & & & \\
\hline & Class V & 0.97 & 0.93 & 0.90 & & & \\
\hline \multirow{5}{*}{$\begin{array}{l}\frac{\tilde{u}}{\bar{c}} \\
\frac{\overline{0}}{\overline{0}} \\
\frac{\overline{0}}{\omega}\end{array}$} & C_upper & 0.94 & 0.88 & 0.85 & 1.40 & 2.10 & 2.51 \\
\hline & C_avg & 0.89 & 0.78 & 0.73 & 2.07 & 3.71 & 4.66 \\
\hline & D_upper & 0.77 & 0.59 & 0.48 & 3.43 & 5.63 & 7.31 \\
\hline & D_avg & 0.65 & 0.54 & 0.35 & 5.68 & 7.41 & 10.92 \\
\hline & D_low & 0.49 & 0.41 & 0.31 & 8.73 & 10.43 & 12.45 \\
\hline
\end{tabular}

\subsubsection{Foundations for rock sites}

Shallow (block) foundations resting on the surface of a homogeneous half-space were designed for rock-profile bridges (Chaudhary, 2017b). Dynamic stiffness of these foundations was calculated by the expressions given by Mylonakis et al. (2006b) for various modes of vibration and are listed in Table 4(a). For a rectangular block foundation of dimensions $2 \mathrm{~B} \times 2 \mathrm{~L}$; with ' $2 \mathrm{~B}$ ' being the shorter dimension and aligned along the longitudinal $(\mathrm{X})$ axis of the bridge, vertical stiffness $\left(K_{z}\right)$, transverse horizontal stiffness, $K_{H x}$ (along the longitudinal axis of the bridge) and longitudinal horizontal stiffness, $K_{H y}$ (along the transverse axis of the bridge) were computed using Eqs. (1) to (3): 
$K_{z}=\frac{2 G_{s} L}{1-v}\left(0.73+1.54 \Xi^{0.75}\right) k_{z}$

$K_{H x}=\frac{2 G_{S} L}{2-v}\left(2+2.50 \Xi^{0.85}\right) k_{x}$

$K_{H y}=\left[K_{H x}-\frac{0.2}{0.75-v} G_{s} L\left(1-\frac{B}{L}\right)\right] k_{y}$

in which $G_{s}$ is the shear modulus of rock, $v$ is its Poisson's ratio, $L$ is the half-length of footing and $\Xi=A / 4 L^{2}$, where $A$ is plan area of the footing. $k_{x}, k_{y}$ and $k_{z}$ are the dynamic stiffness coefficients whose values were determined from charts (Mylonakis et al., 2006b). Values of $k_{x}, k_{y}$ and $k_{z}$ depend on foundation geometry, $v$ and frequency parameter, $a_{0}=\omega B / V_{s}$ in which $\omega$ is the fundamental frequency of the bridge system. Value of $a_{0}$ varied between 0.01 and 0.105 for the bridges considered herein and consequentially values of $k_{x}, k_{y}$ and $k_{z}$ were essentially unity.

Rocking stiffness about the longitudinal axis of footing (i.e. transverse $(Y)$ axis of the bridge), $K_{R y}$ and about the transverse axis of footing (i.e. longitudinal $(\mathrm{X})$ axis of the bridge), $K_{R x}$ were given by Eqs. (4) and (5) as:

$K_{R y}=\left\{\frac{G_{S}}{1-v} I_{b y}^{0.75}\left(\frac{L}{B}\right)^{0.25}\left[2.4+0.5\left(\frac{B}{L}\right)\right]\right\} k_{R y}$

$K_{R x}=\frac{G}{1-v} I_{b x}^{0.75}\left[3\left(\frac{L}{B}\right)^{0.15}\right] k_{R x}$

where $I_{b x}$ and $I_{b y}$ are the area moment of inertia of the foundation-soil contact surface around $X$ and $Y$-axis respectively and $k_{R x}$ and $k_{R y}$ are the dynamic stiffness coefficients that are functions of $a_{0}$. For the range of values of $a_{0}$ in the current study, $k_{R x}$ and $k_{R y}$ were found to be essentially unity.

Numerical values of damping coefficients for block foundations in various rock profiles were determined using expressions and charts of Mylonakis et al. (2006b) and are listed in Table 4 (b). Three values of stiffness and damping coefficients in Table 4 for rock classes III $\sim$ V correspond to DBE, FEE and MCE levels of seismic intensity.

Table 4 (a): Shallow foundation stiffness in various modes for the rock profiles bridges

\begin{tabular}{|c|c|c|c|c|c|c|}
\hline $\begin{array}{l}\text { Rock } \\
\text { Class }\end{array}$ & $\begin{array}{l}\text { Foundation size } \\
\qquad(\mathrm{L} \times \mathrm{B} \times \mathrm{D}) \\
(\mathrm{m} \times \mathrm{m} \times \mathrm{m})\end{array}$ & $\begin{array}{c}\mathrm{K}_{\mathrm{z}} \\
\times 10^{7}(\mathrm{kN} / \mathrm{m})\end{array}$ & $\begin{array}{c}\mathrm{K}_{\mathrm{Hx}} \\
x 10^{7}(\mathrm{kN} / \mathrm{m})\end{array}$ & $\begin{array}{c}\mathrm{K}_{\mathrm{Hy}} \\
x 10^{7}(\mathrm{kN} / \mathrm{m})\end{array}$ & $\begin{array}{c}\mathrm{K}_{\mathrm{Ry}} \\
\mathrm{x} 10^{8}(\mathrm{kN}-\mathrm{m} / \mathrm{rad})\end{array}$ & $\begin{array}{c}\mathrm{K}_{\mathrm{Rx}} \\
\mathrm{x} 10^{9}(\mathrm{kN}-\mathrm{m} / \mathrm{rad})\end{array}$ \\
\hline 1 & $12.6 \times 3.2 \times 1.75$ & 61.9 & 61.7 & 56.6 & 19.4 & 15.7 \\
\hline II & $12.6 \times 3.4 \times 1.75$ & 27.1 & 26.0 & 23.8 & 9.43 & 6.99 \\
\hline III & $12.8 \times 4.0 \times 2.00$ & $9.38,9.38,9.19$ & $8.57,8.57,8.40$ & $7.87,7.87,7.71$ & $4.33,4.33,4.24$ & $2.59,2.59,2.54$ \\
\hline IV & $13.2 \times 5.0 \times 2.25$ & $3.39,3.29,3.19$ & $2.93,2.84,2.76$ & $2.71,2.63,2.55$ & $2.31,2.24,2.17$ & $1.04,1.01,0.98$ \\
\hline V & $14.8 \times 6.0 \times 2.50$ & $2.55,2.37,2.30$ & $2.10,1.95,1.89$ & $1.94,1.80,1.74$ & $2.45,2.28,2.21$ & $1.00,0.93,0.90$ \\
\hline
\end{tabular}

Table 4 (b): Shallow foundation damping coefficient in various modes for the rock profiles bridges

\begin{tabular}{|c|c|c|c|c|c|c|}
\hline Rock Class & $\begin{array}{l}\text { Foundation size } \\
\qquad(\mathrm{L} \times \mathrm{B} \times \mathrm{D}) \\
(\mathrm{m} \times \mathrm{m} \times \mathrm{m})\end{array}$ & $\begin{array}{c}\mathrm{C}_{\mathrm{z}} \\
\times 10^{5}(\mathrm{kN}-\mathrm{s} / \mathrm{m})\end{array}$ & $\begin{array}{c}\mathrm{C}_{\mathrm{Hx}} \\
\mathrm{x} 10^{5}(\mathrm{kN}-\mathrm{s} / \mathrm{m})\end{array}$ & $\begin{array}{c}\mathrm{C}_{\mathrm{Hy}} \\
\times 10^{5}(\mathrm{kN}-\mathrm{s} / \mathrm{m})\end{array}$ & $\begin{array}{c}C_{R y} \\
x 10^{3}(k N-s / m)\end{array}$ & $\begin{array}{c}C_{R x} \\
x 10^{3}(k N-s / m)\end{array}$ \\
\hline 1 & $12.6 \times 3.2 \times 1.75$ & 6.11 & 3.92 & 3.90 & 0.63 & 0.08 \\
\hline II & $12.6 \times 3.4 \times 1.75$ & 4.10 & 2.51 & 2.48 & 1.00 & 0.14 \\
\hline III & $12.8 \times 4.0 \times 2.00$ & $2.69,2.69,2.64$ & $1.55,1.55,1.52$ & $1.54,1.54,1.50$ & $2.30,2.30,2.25$ & $0.39,0.39,0.38$ \\
\hline IV & $13.2 \times 5.0 \times 2.25$ & $1.93,1.87,1.82$ & $1.03,1.00,0.97$ & $1.03,1.00,0.96$ & $5.87,5.69,5.52$ & $1.26,1.22,1.18$ \\
\hline V & $14.8 \times 6.0 \times 2.50$ & $2.37,2.20,2.14$ & $1.14,1.06,1.03$ & $1.14,1.05,1.02$ & $20.69,19.23,18.67$ & $4.80,4.46,4.33$ \\
\hline
\end{tabular}

\subsubsection{Pile-group foundations in soil profiles}

Laterally loaded pile-group foundations were designed for bridges in site classes $C$ and $D$ (Chaudhary, 2018). Procedure of Reese et al. (1984) was used for analysis and design of laterally loaded piles, while use of appropriate p-multipliers took care of the group effect. Figure 2 depicts the pile-group layout in various soil profiles along with the pile diameter and length. 
Dynamic pile-group impedance for long, friction piles installed in a homogeneous half-space was determined using procedure of Dobry and Gazetas (1988) and Makris et al. (1993) that consisted of the following steps:

Step (1) - Determine static single pile stiffness using Eq. (6) (Gazetas, 1984):

$K_{x}^{1}=E_{S} d\left(\frac{E_{P}}{E_{s}}\right)^{0.21}, K_{z}^{1}=19 G_{s} d\left(\frac{L}{d}\right)^{0.67}, K_{R}^{1}=0.15 E_{S} d^{3}\left(\frac{E_{P}}{E_{s}}\right)^{0.75}$

where $E_{s}$ and $G_{s}$ are the soil elastic and shear modulus respectively, $L$ is the pile length, $d$ is the pile diameter and $E_{p}$ elastic modulus of the pile material. Subscripts ' $x$ ', ' $z$ ' and ' $R$ ' refer to lateral, vertical and rocking modes while superscript ' 1 ' refers to a single pile.

Step (2) - Determine dynamic horizontal interaction factor between two piles using Eq. (7) and vertical and rocking interaction factors through Eq. (8) (Makris \& Gazetas, 1992).

$\alpha_{x}(S, \theta)=\frac{3}{4} \psi(S, \theta) \frac{k_{x}(\omega)+i \omega c_{x}(\omega)}{k_{x}(\omega)+i \omega c_{x}(\omega)-m \omega^{2}}$

$\alpha_{Z}(S)=\alpha_{R}(S)=\left(\frac{d}{2 S}\right)^{0.5} \exp \left[-\left(\beta_{S}+i\right) \frac{\omega(S-0.5 d)}{V_{S}}\right]$

in which $k_{x}$ and $c_{x}$ are the soil spring and dashpot coefficients proposed by Gazetas \& Dobry (1984) as: $k_{x} \approx 1.2 E_{s}$ and, $c_{x} \approx 6 a_{0}^{-0.25} \rho_{s} V_{s} d+2 \beta_{s} \frac{k_{x}}{\omega}$, in which $E_{s}, V_{s}, B_{s}$ and $\rho_{s}$ are the elastic modulus, shear wave velocity, damping ratio and mass density of the soil and $a_{0}=\omega d / V_{s}$ is the dimensionless frequency factor. In Eqs. 7 and $8, \psi(S, \vartheta)$ is the attenuation function in which $S$ is the axis to axis distance between two piles and $\vartheta$ is the angle between the direction of loading and
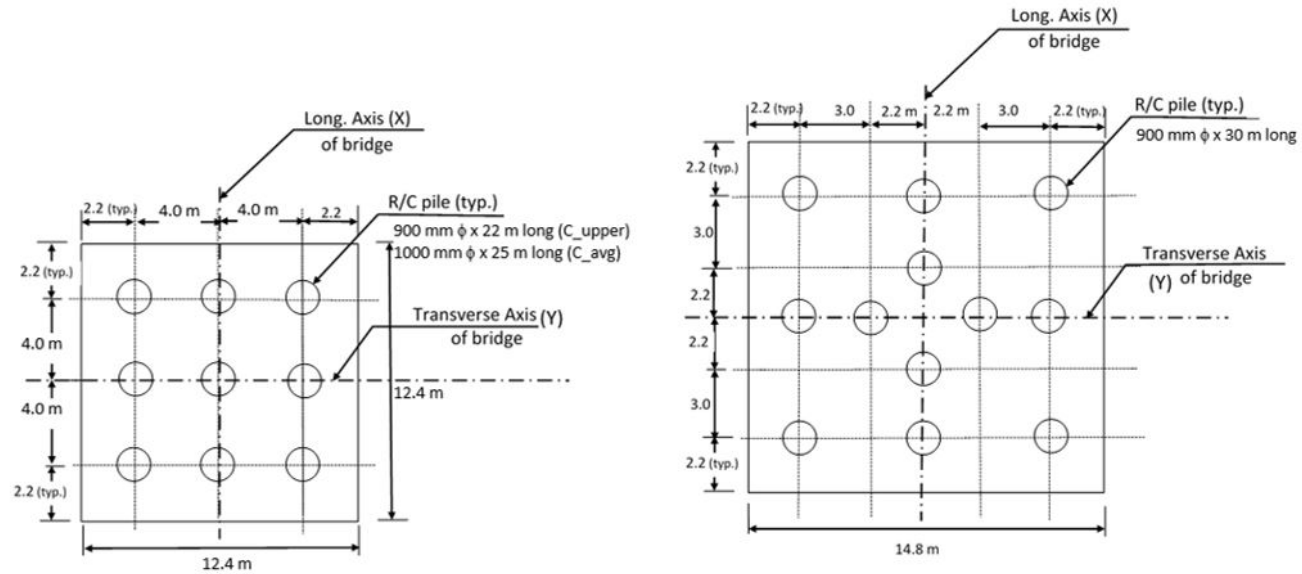

(a)

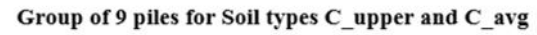

(b)

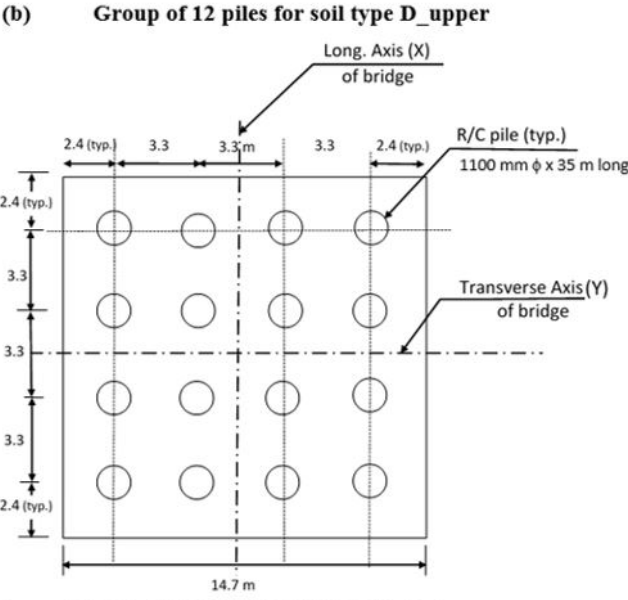

(d)

Group of 16 piles for soil type D_low

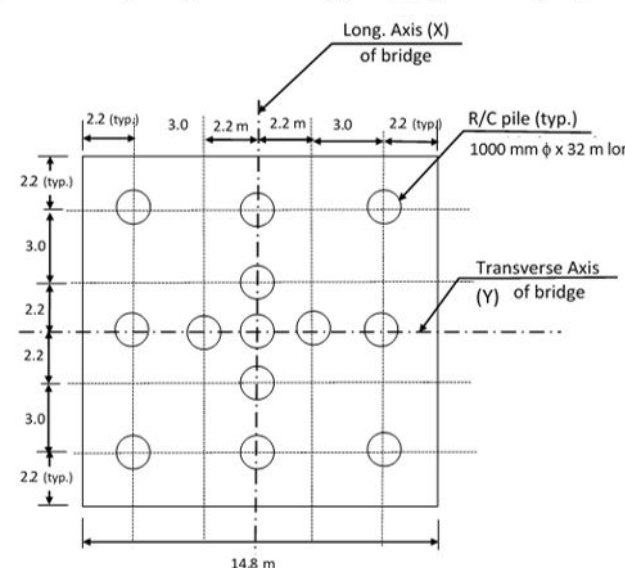

Group of 13 piles for soil type D_avg

Figure 2: Pile group layout in various soil profiles 
the line connecting the axis of the two piles and $m=\rho_{P} A_{p}$ is the mass per unit length of the pile. Approximate expressions for the attenuation function, $\psi(S, \theta)$, are given by Makris and Gazetas (1992) as:

$\psi(S, \theta)=\psi(S, 0)(\operatorname{Cos} \theta)^{2}+\psi\left(S, \frac{\pi}{2}\right)(\operatorname{Sin} \theta)^{2}$

where $\psi(S, 0)=\left(\frac{d}{2 S}\right)^{0.5} \exp \left[-\left(\beta_{S}+i\right) \frac{\omega(S-0.5 d)}{V_{L a}}\right]$

and $\psi\left(S, \frac{\pi}{2}\right)=\left(\frac{d}{2 S}\right)^{0.5} \exp \left[-\left(\beta_{S}+i\right) \frac{\omega(S-0.5 d)}{V_{S}}\right]$

in which $V_{L a}$ is the Lysmer's analogue velocity given by: $V_{L a}=3.4 V_{S} / \pi(1-v)$.

Step (3) - Dynamic Impedance of a pile-group consisting of $N$ piles was found by superposition (Dobry \& Gazetas, 1988 and Makris et al, 1993) for horizontal, vertical and rocking modes using Eq. 12:

$K_{x}^{G}=\bar{K}_{x}^{1} \sum_{i=1}^{N} \sum_{i-1}^{N}\left(\varepsilon_{i j}\right)_{X} ; K_{z}^{G}=\bar{K}_{z}^{1} \sum_{i=1}^{N} \sum_{i-1}^{N}\left(\varepsilon_{i j}\right)_{z} ; K_{R}^{G}=\bar{K}_{z}^{1} \sum_{i=1}^{N} x_{i} \sum_{i-1}^{N}\left(\varepsilon_{i j}\right)_{z} x_{j}$

where $\left(\varepsilon_{i j}\right)_{X}=\left[\alpha_{X}(S, \theta)\right]^{-1}$ and $\left(\varepsilon_{i j}\right)_{Z}=\left[\alpha_{Z}(S)\right]^{-1}$ are the inverse of horizontal and vertical pile group interaction matrix respectively and $x_{i}$ is the distance of pile $i$ from the axis about which rotation occurs and $G$ in the superscript refres to pile group.

It is to be noted that the dynamic pile-group impedances computed by the above procedure are frequencydependent complex-valued quantities in which real and imaginary parts represent stiffness and damping coefficient respectively. As suggested in NIST (2012), frequency-independent stiffness and damping coefficients were adopted for the median value of fundamental frequency of the bridges for a particular soil profile and seismic intensity. These frequency-independent values of pile-group stiffness and damping coefficients in various modes of vibrations are listed in Tables 5(a) and 5(b) respectively. Subscript ' 0 ' refers to small strain values in these Tables.

Table 5 (a): Pile-group stiffness for various soil profiles and earthquake levels

\begin{tabular}{|c|c|c|c|c|c|c|c|c|c|c|c|c|}
\hline \multirow{2}{*}{ Soil } & \multicolumn{4}{|c|}{$K_{h}\left(x 10^{6}\right) \mathrm{kN} / \mathrm{m}$} & \multicolumn{4}{|c|}{$K_{v}\left(x 10^{6}\right) \mathrm{kN} / \mathrm{m}$} & \multicolumn{4}{|c|}{$\mathrm{K}_{\mathrm{R}}\left(\mathrm{x} 10^{8}\right) \mathrm{kN}-\mathrm{m} / \mathrm{rad}$} \\
\hline & $\mathrm{K}_{\mathrm{ho}}$ & DBE & FEE & MCE & $\mathrm{K}_{\mathrm{v} 0}$ & DBE & FEE & MCE & $\mathrm{K}_{\mathrm{r} 0}$ & DBE & FEE & MCE \\
\hline C_upper & 9.38 & 8.99 & 8.55 & 8.34 & 26.40 & 25.31 & 23.81 & 23.06 & 6.13 & 5.89 & 5.55 & 5.37 \\
\hline C_avg. & 6.86 & 6.21 & 5.61 & 5.29 & 17.69 & 15.82 & 13.90 & 12.94 & 4.35 & 3.91 & 3.45 & 3.21 \\
\hline D_upper & 5.12 & 4.17 & 3.40 & 2.86 & 13.76 & 10.65 & 8.20 & 6.60 & 7.71 & 5.99 & 4.61 & 3.71 \\
\hline D_avg. & 3.55 & 2.55 & 2.20 & 1.56 & 8.18 & 5.37 & 4.47 & 2.88 & 4.91 & 3.26 & 2.72 & 1.77 \\
\hline D_low & 1.77 & 1.01 & 0.87 & 0.70 & 3.24 & 1.59 & 1.32 & 1.00 & 1.85 & 0.98 & 0.83 & 0.65 \\
\hline
\end{tabular}

Table 5 (b): Pile-group damping coefficient for various soil profiles and earthquake levels

\begin{tabular}{|c|c|c|c|c|c|c|c|c|c|}
\hline \multirow{2}{*}{ Soil } & \multicolumn{3}{|c|}{$C_{h}\left(\times 10^{5}\right) \mathrm{kN}-\mathrm{s} / \mathrm{m}$} & \multicolumn{3}{|c|}{$C_{v}\left(\times 10^{5}\right) \mathrm{kN}-\mathrm{s} / \mathrm{m}$} & \multicolumn{3}{|c|}{$C_{R}\left(\times 10^{6}\right) \mathrm{kN}-\mathrm{s} / \mathrm{m}$} \\
\hline & DBE & FEE & MCE & DBE & FEE & MCE & DBE & FEE & MCE \\
\hline C_upper & 3.23 & 3.17 & 3.15 & 3.32 & 3.22 & 3.13 & 9.26 & 8.95 & 8.81 \\
\hline C_avg. & 2.89 & 2.78 & 2.72 & 2.98 & 2.81 & 2.67 & 9.07 & 8.47 & 8.16 \\
\hline D_upper & 1.66 & 1.60 & 1.49 & 3.04 & 2.91 & 2.63 & 8.61 & 7.68 & 7.03 \\
\hline D_avg. & 0.88 & 0.83 & 0.74 & 2.13 & 1.92 & 1.56 & 7.64 & 7.16 & 6.20 \\
\hline D_low & 0.45 & 0.43 & 0.39 & 0.67 & 0.61 & 0.53 & 4.99 & 4.74 & 4.41 \\
\hline
\end{tabular}

\subsection{Design and modeling of pier columns}

\subsubsection{Cross section and material properties}

Figure 3 (a) depicts the cross sectional details of the $2 \mathrm{~m}$ square reinforced concrete $(\mathrm{R} / \mathrm{C})$ pier columns that were designed according to the AASHTO code stipulated combinations of dead, live and seismic loads following the prevailing design practices for dimensioning and detailing. Concrete with design compressive strength $\left(f_{c}{ }^{\prime}\right)$ of $27.6 \mathrm{MPa}$ and having 
stress-strain model proposed by Thorenfeldt et al (1987) was used in design and section analysis. Concrete had tensile strength of $1.70 \mathrm{MPa}$; strain at peak compressive stress of $0.0023 \mathrm{~mm} / \mathrm{mm}$ and initial elastic modulus of $24.34 \mathrm{GPa}$. Deformed steel reinforcing bars with a yield stress of $420 \mathrm{MPa}$, ultimate stress of $630 \mathrm{MPa}$, modulus of elasticity, E, of $200 \mathrm{GPa}$, strain at the start of strain hardening of $7 \mathrm{~mm} / \mathrm{m}$ and strain at ultimate stress of $100 \mathrm{~mm} / \mathrm{m}$ were used in design and section analysis.

\subsubsection{Modeling of pier inelasticity}

Non-linear behavior of the pier columns was captured by employing hinge elements at column ends in the FEM numerical model. Plastic hinge length $\left(L_{p}\right)$ was computed as (Paulay \& Priestley, 1992): $L_{p}=0.08 L+0.022 f_{y} d_{b}$, where $L$ is the shear span and $d_{b}$ is diameter of the longitudinal bars. Parameters of the plastic hinge were defined manually in SAP2000 through definition of $L_{p}$ and input of moment-curvature $(M-\phi)$ data of the cross section. $M-\varphi$ relationship for the $\mathrm{R} / \mathrm{C}$ pier column section subjected to the combined actions of axial load, bending moment and shear force was found by a layer-by-layer strain compatibility analysis in computer program Response-2000 (Bentz, 1999). Response-2000 used modified compression field theory (Vecchio and Collins, 1986) while relating stresses and strains at various locations across the section and allowed for tension stiffening effect of concrete (Collins and Mitchell, 1991). Figure 3 (a) presents the $M-\varphi$ relationship for the pier section, while lateral load vs deflection relationship $(F-\delta)$ of the pier column that was obtained by double integrating the $M-\varphi$ relationship is presented in Figure 3 (b) along with variation in secant stiffness of the pier column with lateral displacement (i.e. $k-\delta$ relationship).

\section{SEISMIC GROUND MOTIONS}

A suite of twenty-one actual strong motion records, selected from the literature (Katsanos, et al., 2010; ATC-63, 2008) and matching the design spectra of the bridge site was used in the study. Figure 4 presents the acceleration spectra of three groups of selected ground motions (i.e. DBE, FEE and MCE) used in the study while the salient details of these ground motions are presented in the Appendix Table A1. Seismic records representing DBE, FEE and MCE ground motions had a return period of 500, 1000 and 2500 years and PGA of $0.04-0.23 \mathrm{~g}, 0.27-0.36 \mathrm{~g}$ and $0.38-0.61 \mathrm{~g}$ respectively. Strong motion records were obtained from the online database of Pacific Earthquake Engineering Research center (PEER NGA-West2, 2018).

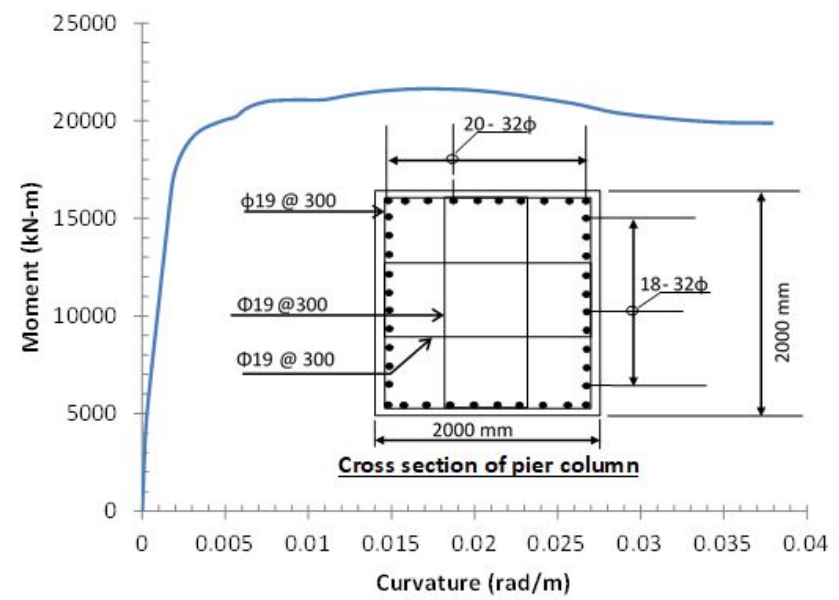

(a)

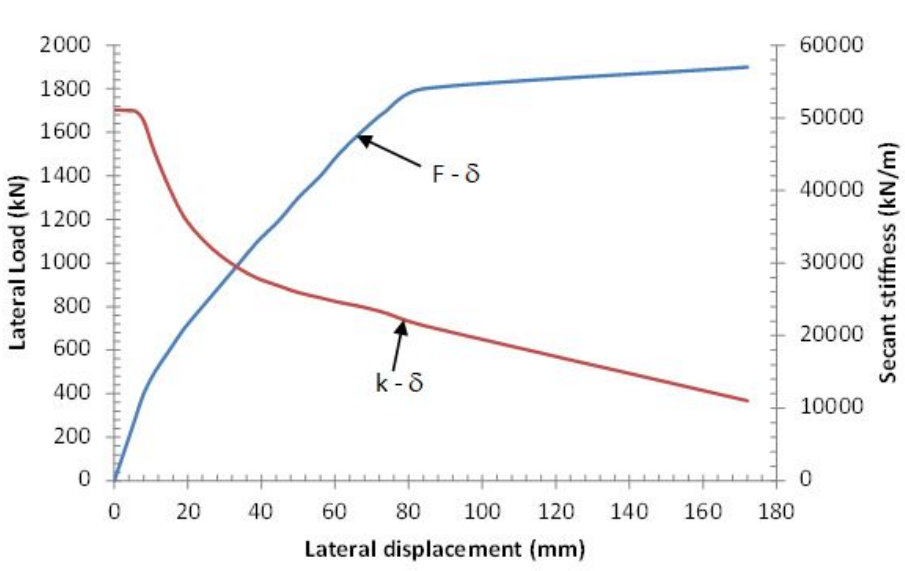

(b)

Figure 3: (a) Pier column cross section and $\mathrm{M}-\varphi$ relationship, (b) lateral load and secant stiffness variation with lateral displacement 


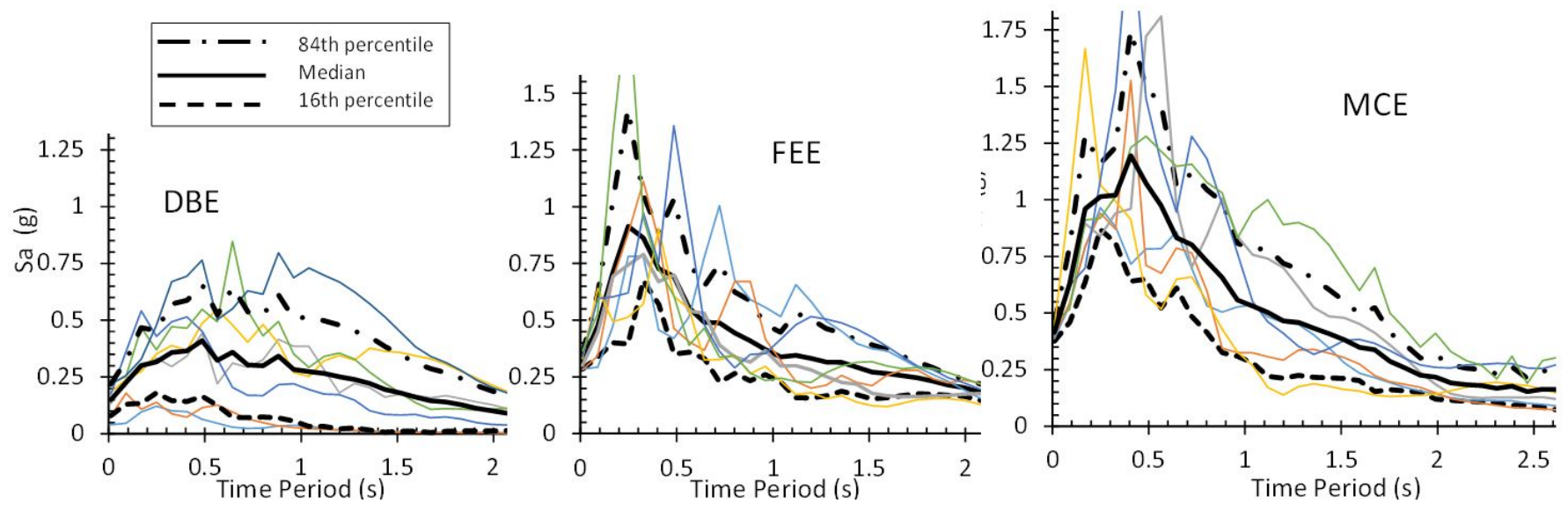

Figure 4: Spectral acceleration of used seismic ground motions

\section{FEM MODELING AND ANALYSIS OF THE BRIDGE SYSTEM}

\subsection{FEM modeling}

The bridge system was modeled in FEM package SAP2000 (CSI, 2019) as depicted in Figure 5. SSI in the FEM model was incorporated through sub-structuring and was represented by Winkler springs and dashpots. Two different types of finite elements were used to model the bridge super-structure. Bridge girders and diaphragms were modeled by six degree-of-freedom (DOF) Timoshenko beam elements that incorporated shear deformations, while the bridge deck was represented by four-node plate elements that included Mindlin-Reissner bending theory for thick shells. Intersecting girder, diaphragm and slab nodes were assumed rigid due to the composite action between these elements. Sub-structure consisted of pier columns, pier cap and pile cap; all of which were modeled by Timoshenko beam elements with six-DOF at each node.

Pier columns consisted of two different types of elements. The end zones of pier columns were modeled with nonlinear hinge elements whose properties were determined as described in Section 3.3.2. Interior parts of the pier columns were modeled with elastic beam elements. Similarly, for the analysis cases with elastic pier, non-linear hinge elements were replaced with elastic beam elements. Connections between the pier cap and bridge girders were through ordinary bearings and were modeled in FEM through rigid links. Pier cap and super-structure elements were not designed to undergo inelastic action and were therefore modeled to remain elastic. Soil-foundation system was represented with equivalent-linear Winkler springs and dashpots whose values were obtained through non-linear procedures as described in Section 3.2.

\subsection{Analysis cases}

Four types of FEM models with different boundary conditions were analyzed. The models were: (a) Fixed base with elastic pier, (b) Fixed base with inelastic pier, (c) SSI with elastic pier and (d) SSI with inelastic pier. These four types of models were executed for 21 seismic ground motions and 11 soil profiles (five rock and soil conditions each and one fixed base case) resulting in more than 450 FEM analysis cases. 


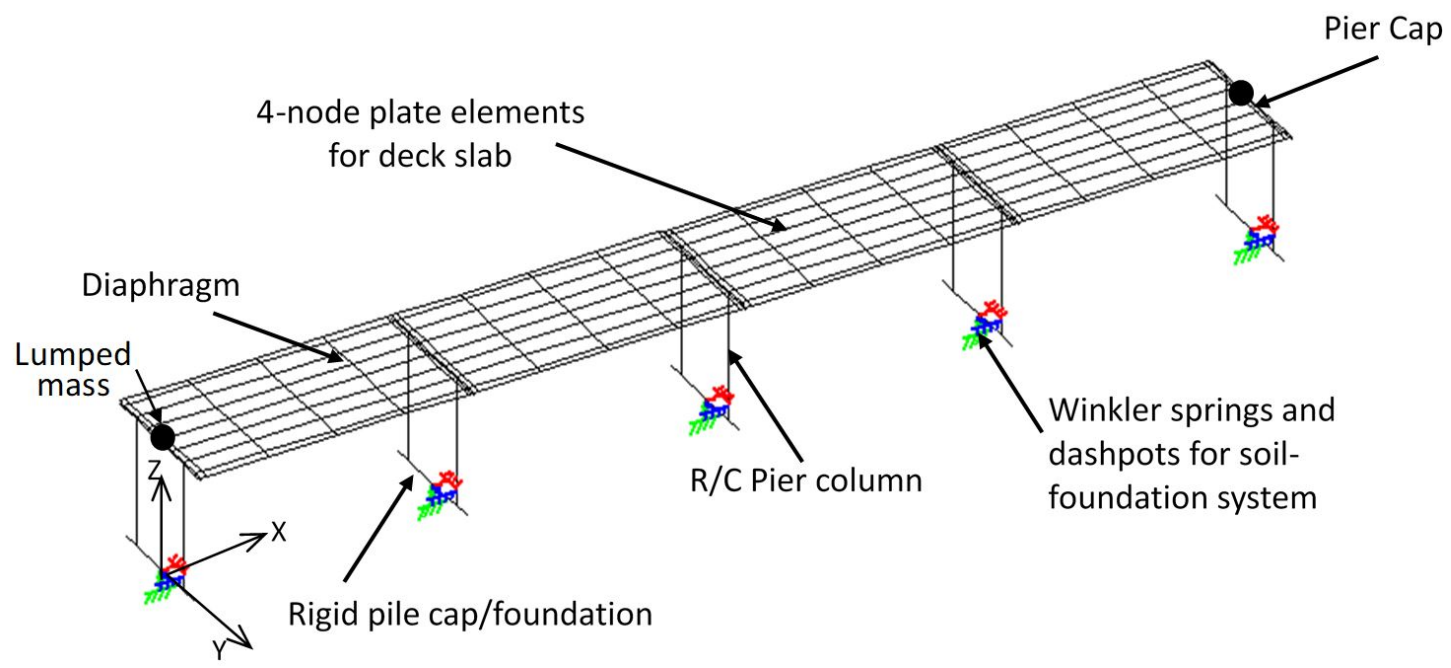

Figure 5: FEM model of the bridge

\subsection{Non-linear dynamic time history analysis}

Non-linear dynamic time-history analysis was performed using direct integration employing the unconditionally stable Newmark- $\beta$ method with $\beta$ value of 0.25 as recommended in the technical manual of SAP 2000 (CSI, 2019). This solution method allowed the use of viscous proportional damping for the structure. SAP2000 automatically assigns translational mass of all elements to the corresponding joints. However, rotational masses were manually assigned based on tributary length and sectional properties as outlined in SAP2000 technical manual (CSI, 2019). Effect of the adjacent spans of the viaduct was included by assigning half mass of the adjacent span as a lumped mass on the end piers as depicted in Figure 5. Seismic ground motions were input in the longitudinal and transverse directions according to AASHTO, 2017. Linear modal analysis was conducted the end of non-linear time-history analysis that utilized reduced stiffness obtained at the end of the non-linear time-history analysis for eigenvalue analysis. A non-linear time-history analysis was not carried out for analysis cases with elastic pier columns. FEM analysis results related to the modal parameters of the bridges are presented and discussed in the next section.

\section{MODAL FREQUENCIES AND THEIR VARIATIONS}

\subsection{Frequency variation}

This section describes the variation in modal frequencies noted in the FEM analysis for various boundary condition (fixed and SSI cases) for elastic and inelastic pier columns of the bridge system in various rock and soil profiles.

\subsubsection{Elastic pier column}

Figures $6(\mathrm{a})$ and $6(\mathrm{~b})$ present changes in the five lower modal frequencies of the bridge with elastic pier columns for various boundary conditions and three levels of seismic intensities for rock and soil profile bridges respectively. The change in modal frequencies for bridges with elastic pier columns was only due to the variation in rock/soil-foundation impedances (i.e. SSI effect only) as there was no change in stiffness of the elastic pier column due to varying intensity of the seismic input motion. It was noted in Figure 6(a) that the maximum modal frequency variation across the three levels of seismic intensity for rock profile bridges within a rock class was: Classes I \& II ( $0 \%$ as rock-foundation impedance did not change across the three levels of seismic excitations), Class III $(0.9 \%$, mode 3$)$, Class IV $(1.4 \%$, mode 2$)$ and Class V (2.9\%, mode 2$)$. The same values for soil-profile bridges [Figure $6($ b)] were: C_upper $(0.4 \%$, mode 4$)$, C_avg $(1.0 \%$, mode 1$)$, D_upper (1.4\%, mode 3$)$, D_avg $(2.7 \%$, mode 3$)$ and D_low $(4.3 \%$, mode 3$)$.

According to the results plotted in Figure 6, maximum variation in frequency in a mode was $5.4 \%, 4.7 \%, 2.4 \%, 5.0 \%$ and $1.8 \%$ for modes 1 to 5 respectively in rock profile bridges and $12.7 \%, 20.5 \%, 17.0 \%, 5.7 \%$ and $5.1 \%$ for modes 1 to 5 respectively for soil profile bridges.

It was also noted that frequencies in any particular mode progressively reduced from the fixed base condition to the weaker soil/rock cases. In addition, the magnitude of variation in modal frequencies generally reduced with increasing mode order except for mode 4 in rock profile and mode 2 in soil profile bridges. 


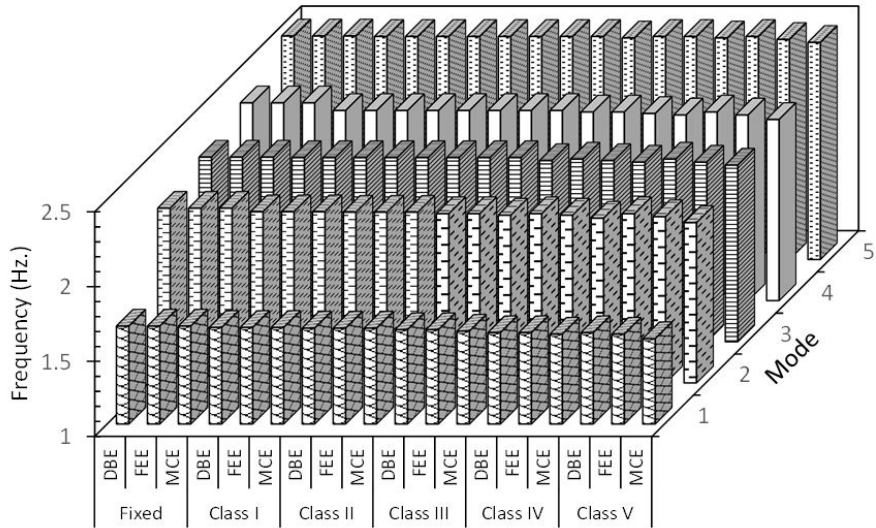

(a) Rock profile bridges

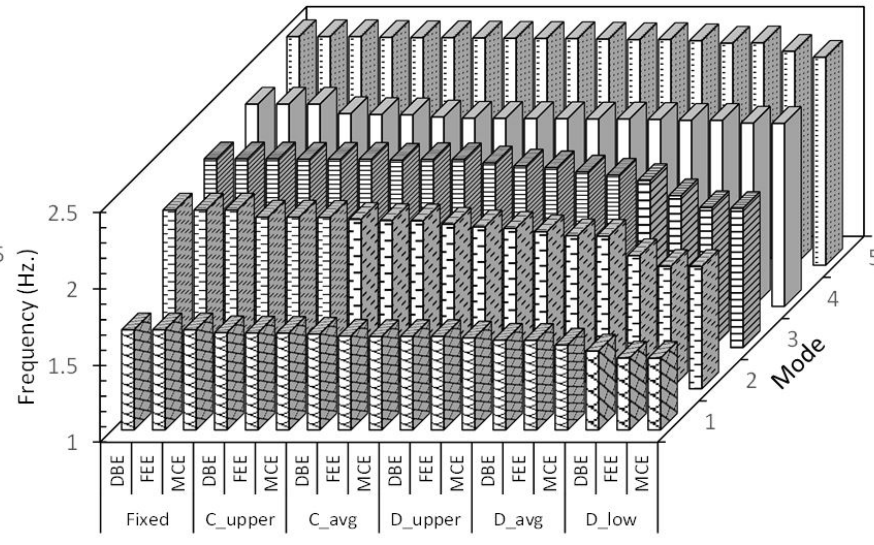

(b) Soil profile bridges

Figure 6: Variation in modal frequencies for elastic pier column. (a) Rock profile bridges, (b) Soil profile bridges

\subsubsection{Inelastic pier column}

For the analysis cases that included pier column inelasticity, modal frequencies changed due to variations in pier column stiffness as well as due to the changes in support boundary conditions (i.e. fixed-base or soil/rock-foundation impedances). The values of pier column stiffness changed according to the maximum level of lateral displacement caused by a particular ground motion and were determined through non-linear time-history analysis. Figures 7 (a) \& (b) depict variation in pier column stiffness as obtained from the FEM analysis results for the rock and soil profile bridges respectively. A strong correlation between pier column stiffness reduction and PGA was noted for both rock and soil profile bridges as coefficient of determination $\left(R^{2}\right)$ was 0.895 and 0.867 for rock and soil profile bridges respectively that resulted in a coefficient of correlation ( $R$ ) of 0.95 and 0.93 for rock and soil profile bridges respectively. Corresponding changes in the soil/rock-foundation impedances are listed in Tables 4 and 5 for shallow foundation in rock profiles and pile-group foundations in soil profiles respectively.
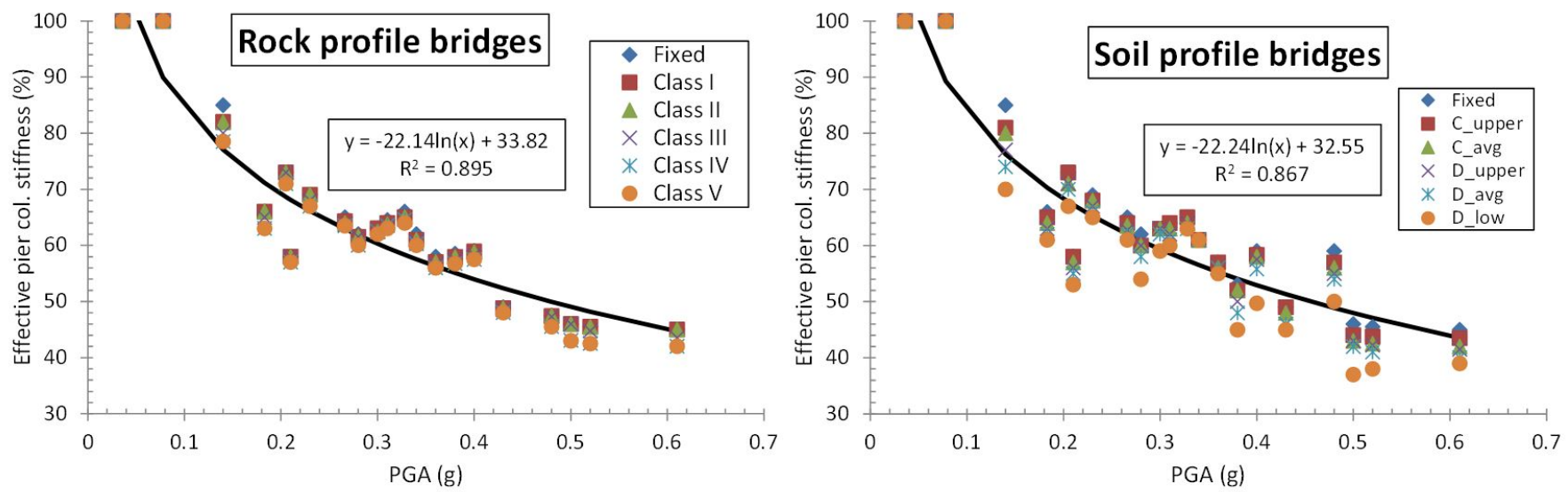

Figure 7: Variation in pier column stiffness with PGA. (a) Rock profile bridges, (b) Soil profile bridges

Figures 8 and 9 present variation in the first four modal frequencies of bridges with inelastic pier columns as a function of PGA in rock and soil profiles respectively. An examination of Figure 8 revealed that for the rock profile bridges, the first modal frequency exhibited a decrease of $22 \%$ across all seismic records (PGA: $0.036 \mathrm{~g}-0.61 \mathrm{~g}$ ) for the fixed base bridges. Whereas, for bridges in the weakest rock profile (Class V), the corresponding decrease in the first modal frequency was $23 \%$. The $2 \mathrm{nd}$ modal frequency showed a maximum decrease of $21 \%$ and $22 \%$ for the fixed-base and rock Class $\mathrm{V}$ cases respectively across all seismic records. The same numbers for decrease in the $3 \mathrm{rd}$ modal frequency were $18 \%$ and $21 \%$. However, a change of only $5 \%$ and $4 \%$ was noted in the 4 th modal frequency for bridges with fixed base and SSI in rock Class $\mathrm{V}$ cases respectively. The maximum change in frequency across all seismic motions for bridges in soil profiles as determined from Figure 9 was: $23 \%, 21 \%, 19 \%$ and $6 \%$ for modes 1 to 4 respectively for bridges with a fixed base and $29 \%, 31 \%, 28 \%$ and $8 \%$ for the ones in the weakest soil profile (i.e. D_low). 

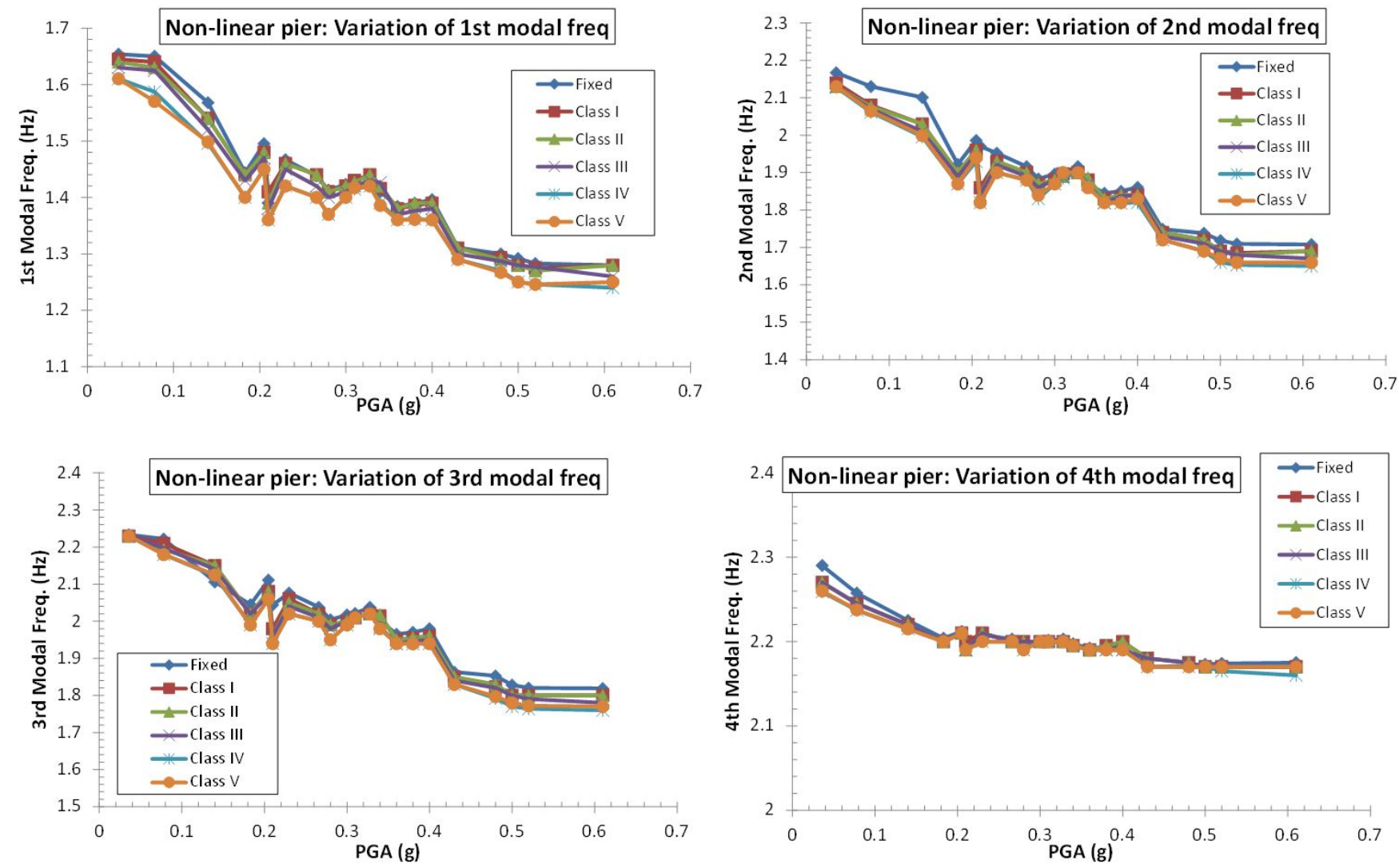

Figure 8: Variation in modal frequencies in rock profile bridges with inelastic pier columns
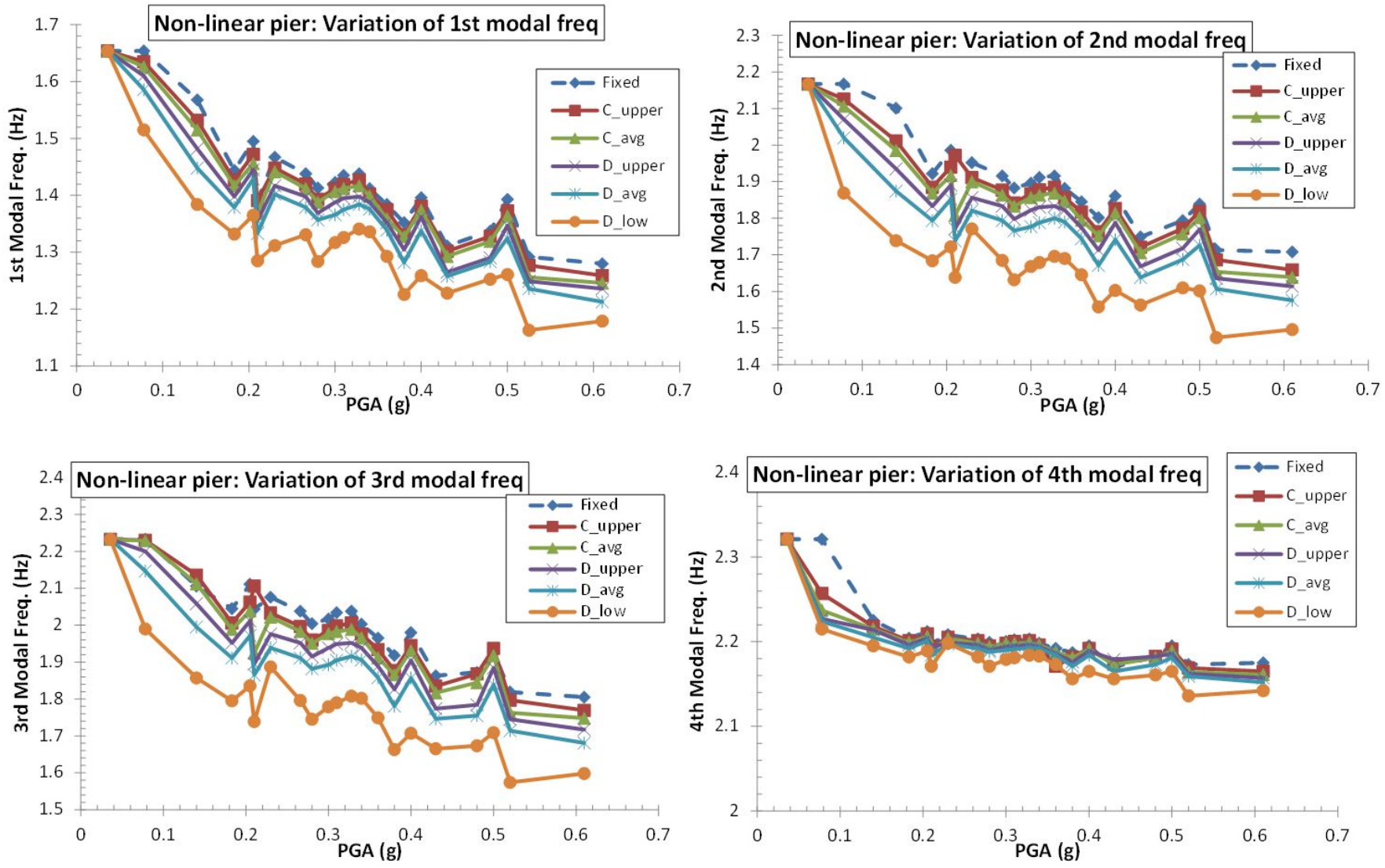

Figure 9: Variation in modal frequencies in soil profile bridges with inelastic pier columns 
A clear trend of gradual decrease in modal frequency with increasing PGA and decreasing soil/rock shear modulus $\left(G_{s}\right)$ was noted in Figures 8 and 9. Decrease in modal frequency with PGA was relatively steep for the first three modes of vibration for bridges in rock as well as soil profiles. However, the 4th modal frequency exhibited the least variation with respect to $P G A$ and $G_{s}$ for bridges in both rock and soil profiles.

It was also observed that the range of change in frequency decreased with an increase in the order of the modal frequency. Consequentially, it can become increasingly difficult to detect any significant change in the modal frequency with increasing modal order due to an increasingly smaller range of frequency change. This observation implies that the task of identifying localized damage in a bridge system can be fraught with difficulties as presence of such damage usually manifests itself as a change in higher modal frequencies. The smaller change in higher modal frequencies is also indicative of these modes not being sensitive to changes in pier column stiffness and/or SSI.

\subsection{Sensitivity of modal frequencies to SSI and pier column inelasticity}

\subsubsection{Elastic Pier Column}

Modal frequencies varied for the elastic pier column cases only due to changes in the values of foundation impedances. This variation was depicted in Figures $6(\mathrm{a})$ \& (b) for rock profile and soil profile bridges respectively. Therefore, in the case of elastic pier, $100 \%$ contribution to frequency change for various analysis cases was due to SSI. It was noted in Section 6.1.1 that maximum variation in frequency for the first five modes for rock profile and soil profile bridges for elastic pier columns was in the ranges of $2.4 \sim 5.4 \%$ and $5.1 \sim 20.5 \%$ respectively.

It was mentioned in section 1 that a number of researchers made the assumption of elastic pier columns in their studies related to changes in modal properties due to SSI. It will be explained in section 6.2.3 that this assumption may not be valid when seismic intensity exceeds a certain limit.

\subsubsection{Inelastic pier column}

It was noted in section 6.1.2 that stiffness degradation in pier columns as well as changes in soil-foundation impedances were responsible for variation in modal frequencies of bridges with inelastic pier columns. An attempt was made in this section to quantify sensitivity of modal frequencies to the effects of SSI and pier inelasticity for the first four modes of vibration. Sensitivity of frequency variation $(\Delta f)$ in a particular case, as compared to the elastic-fixed case, to the effects of pier inelasticity and SSI was computed by the following expressions:

$$
\begin{aligned}
& (\Delta f)_{\text {pier }}=\left(f_{\text {fixed }}^{\text {elastic }}-f_{\text {fixed }}^{\text {inelastic }}\right) / f_{\text {fixed }}^{\text {elastic }} \\
& (\Delta f)_{S S I}=\left(f_{\text {fixed }}^{\text {inelastic }}-f_{S S I}^{\text {inelastic }}\right) / f_{\text {fixed }}^{\text {elastic }}
\end{aligned}
$$

Figures 10 and 11 depict the contribution of pier column inelasticity and SSI components towards changes in modal frequencies for the rock and soil profile bridges respectively. In these figures, maximum change in frequency $(\Delta f)_{\max }$ for a particular case was computed as:

$$
(\Delta f)_{\max }=(\Delta f)_{p i e r}+(\Delta f)_{S S I}^{\max }
$$

where $(\Delta f)_{S S I}^{\max }$ is the maximum value of change in frequency for all rock (or soil) profiles for a particular seismic motion.

Contribution of SSI to frequency change for the elastic pier case for the weakest rock (Class V) and soil (D_low) profiles are also depicted in Figure 10 and 11. It was observed that contribution of SSI towards change in modal frequency for the first four modes was almost double for the elastic pier cases as compared to the inelastic pier cases. It was also noted that share of SSI towards frequency change increased with increasing seismic intensity for the elastic pier cases. However, for the inelastic pier cases, SSI contribution increased up to a PGA value of $0.2 \mathrm{~g}$ and then started to reduce afterwards. This reduction was due to the increased contribution from pier column inelasticity.

An examination of Figures 10 and 11 revealed that sensitivity of SSI towards change in modal frequency increased with decreasing rock/soil strength for all four modes. It was also noted in these figures that pier column inelasticity was the most dominant factor that caused changes in modal frequency in all modes for all seismic ground motions in rock and soil profile bridges. However, the share of SSI towards changes in 2 nd and 3rd modal frequencies for both rock and soil profile bridges was more than the 1st and 4th modes. Reason for this anomaly is explained later in section 6.2.3. 


\subsubsection{Contribution of pier inelasticity and SSI to frequency change and implication for FEM model updating}

Figures 12 and 13 provide holistic trends of sensitivity of first four modal frequencies to soil-foundation impedance (SSI effect) for bridges in five rock and five soil profiles with respect to PGA. It was noted that contribution of SSI towards frequency change was the highest for the lowest magnitude seismic motions (i.e. DBE) and it reduced with increasing seismic intensity of FEE and MCE ground motions for bridges in all rock and soil profiles. However, contribution of SSI towards frequency change increased with decreasing soil/rock strength. Additionally, modal frequencies showed more sensitivity to SSI in soil profile bridges as compared to rock profile bridges for all four modes. It was also noted that contribution of SSI to frequency change was more in modes 2 and 3 as compared to modes 1 and 4 for both rock and soil profile bridges.
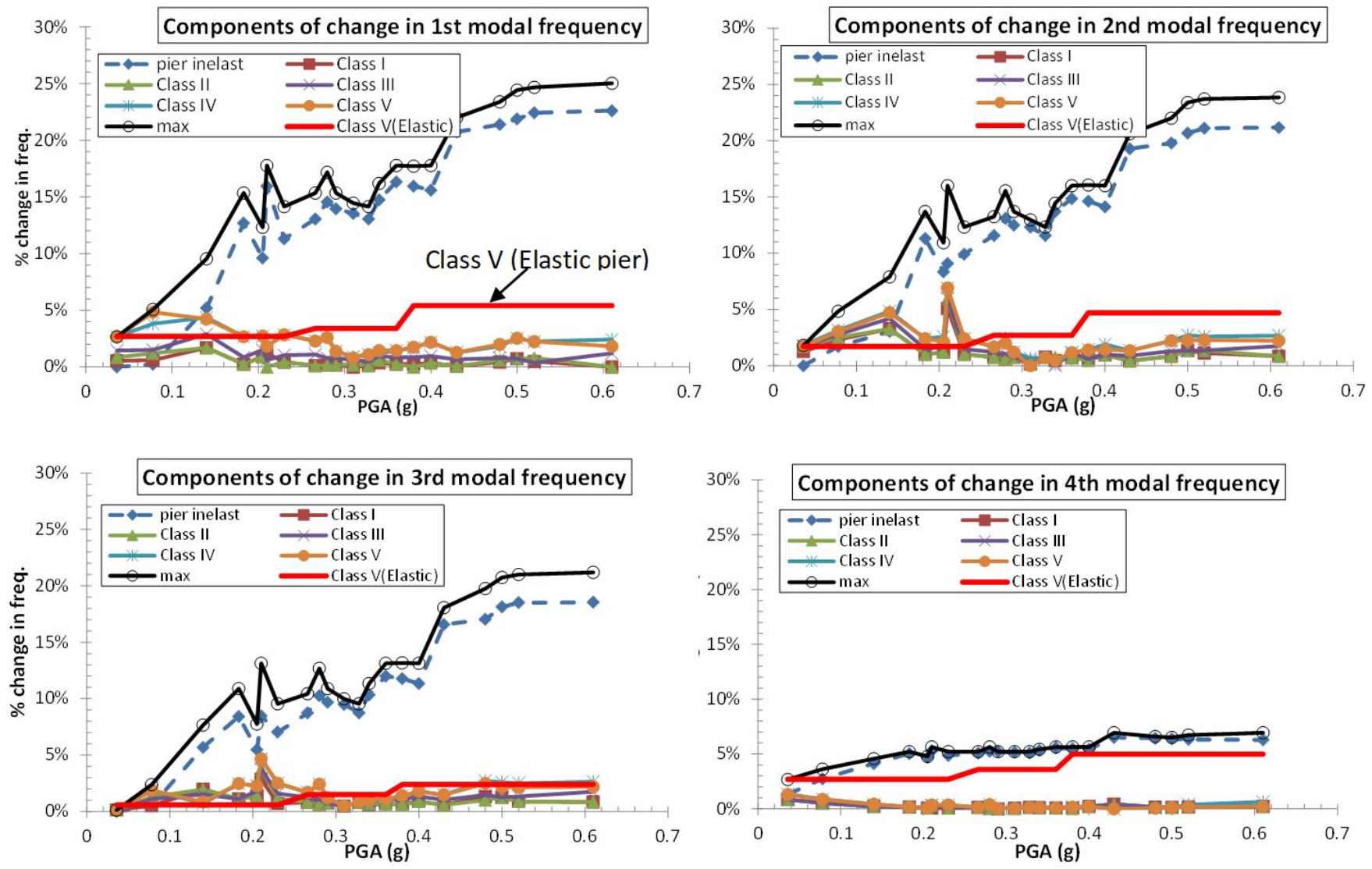

Figure 10: Components of change in modal frequencies as compared to the fixed-elastic case for inelastic pier column - rock profile bridges 

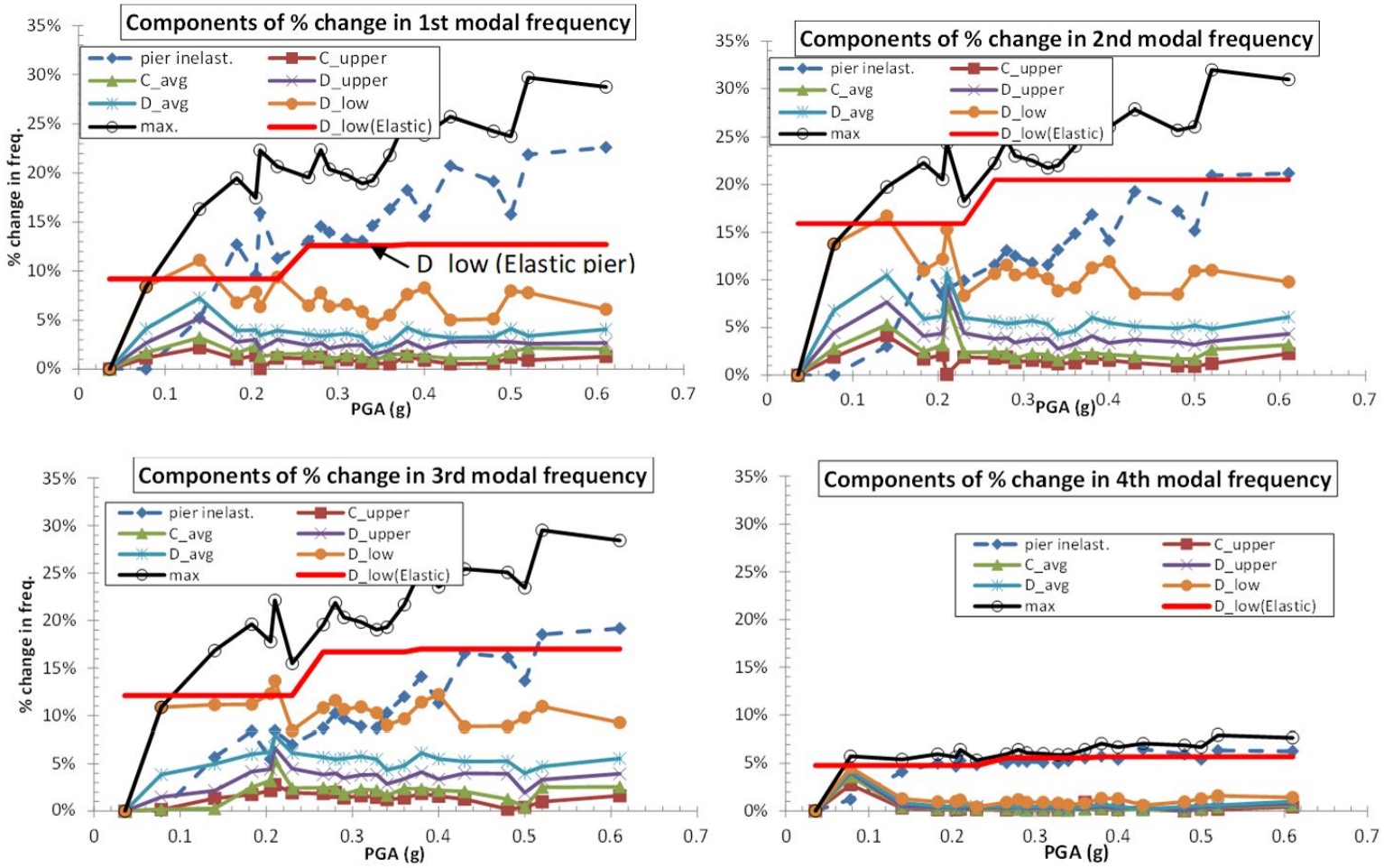

Figure 11: Components of change in modal frequencies as compared to the fixed-elastic case for inelastic pier column - soil profile bridges

In order to make generalized conclusions about the sensitivity of changes in first four modal frequencies to SSI and pier column inelasticity, data presented in Figures 12 and 13 was aggregated in Figures 14 and 15 respectively. In Figures 14 and 15 , average share $(\Lambda)$ of pier inelasticity and SSI for a seismic intensity level across all rock or soil profiles towards change in a modal frequency was determined as follows:

$\Lambda_{\text {pier }}=\frac{1}{m} \sum_{n=1}^{m}\left[\frac{(\Delta f)_{p i e r}}{(\Delta f)_{p i e r}+\frac{1}{p} \sum_{i=1}^{p}(\Delta f)_{S S I}}\right]_{n}$

$\Lambda_{S S I}=1-\Lambda_{\text {pier }}$

where $m$ is the number of seismic ground motions in a seismic intensity level and $p$ is the number of rock or soil profiles.

As depicted in Figure 14, contribution of pier column inelasticity towards changes in the first and fourth modal frequencies in DBE level of seismic motions for rock profile bridges was $72 \%$ and $84 \%$ respectively while this contribution decreased to $65 \%$ and $66 \%$ for modes 2 and 3 respectively. Contrarily, contribution of pier column inelasticity towards change in modal frequencies for FEE and MCE ground motions was more than $90 \%$ for all modes and varied between $90 \%$ to $97 \%$. The corresponding contribution of pier column inelasticity, as depicted in Figure 15, for DBE level for modes 1 and 4 for soil profile bridges was $60 \%$ and $80 \%$ respectively. However, share of pier column inelasticity showed a marked decrease for modes 2 and 3 and its value was $42 \%$ and $44 \%$ respectively. Unlike the rock profile bridges (Figure 14), contribution of SSI towards frequency change for FEE and MCE levels was significant and varied between $10 \%$ to $35 \%$ for FEE motions and $6 \%$ to $25 \%$ for MCE motions. Similar to the rock profile bridges, contribution of SSI was significantly more in modes 2 and 3 for all three levels of seismic intensities as compared to modes 1 and 4 . Reason for this disparity is explained in section 6.2.3.3.

Also noted in Figures 14 and 15 are the median values of rock/soil stiffness reduction $\left(G / G_{0}\right)$ and pier column stiffness reduction $\left(k_{c} / k_{c o}\right)$ for the rock and soil profiles bridges respectively for the three levels of seismic intensity. Values of $G / G_{0}$ for DBE, FEE and MCE levels showed variations of $1.0-0.97,1-0.93$ and $1-0.90$ for the rock profile bridges and $0.94-0.49,0.88-0.41$ and $0.85-0.31$ for the soil profile bridges respectively. Corresponding variations in $k_{c} / k_{c 0}$ were: $1-0.7,0.7-0.58$ and $0.58-0.46$ for the rock profile bridges and $1-0.66,0.66-0.56$ and $0.56-0.45$ for the soil profile bridges for the three levels of seismic intensities respectively. It can be noted that variations in pier column 
stiffness reduction for the rock and soil profile bridges is nearly the same for the three levels of seismic intensities. However, the corresponding variations in $G / G_{0}$ are markedly different in rock and soil profile bridges with soil profile bridges exhibiting a much higher reduction in $G / G_{0}$ as compared to the rock profile bridges.
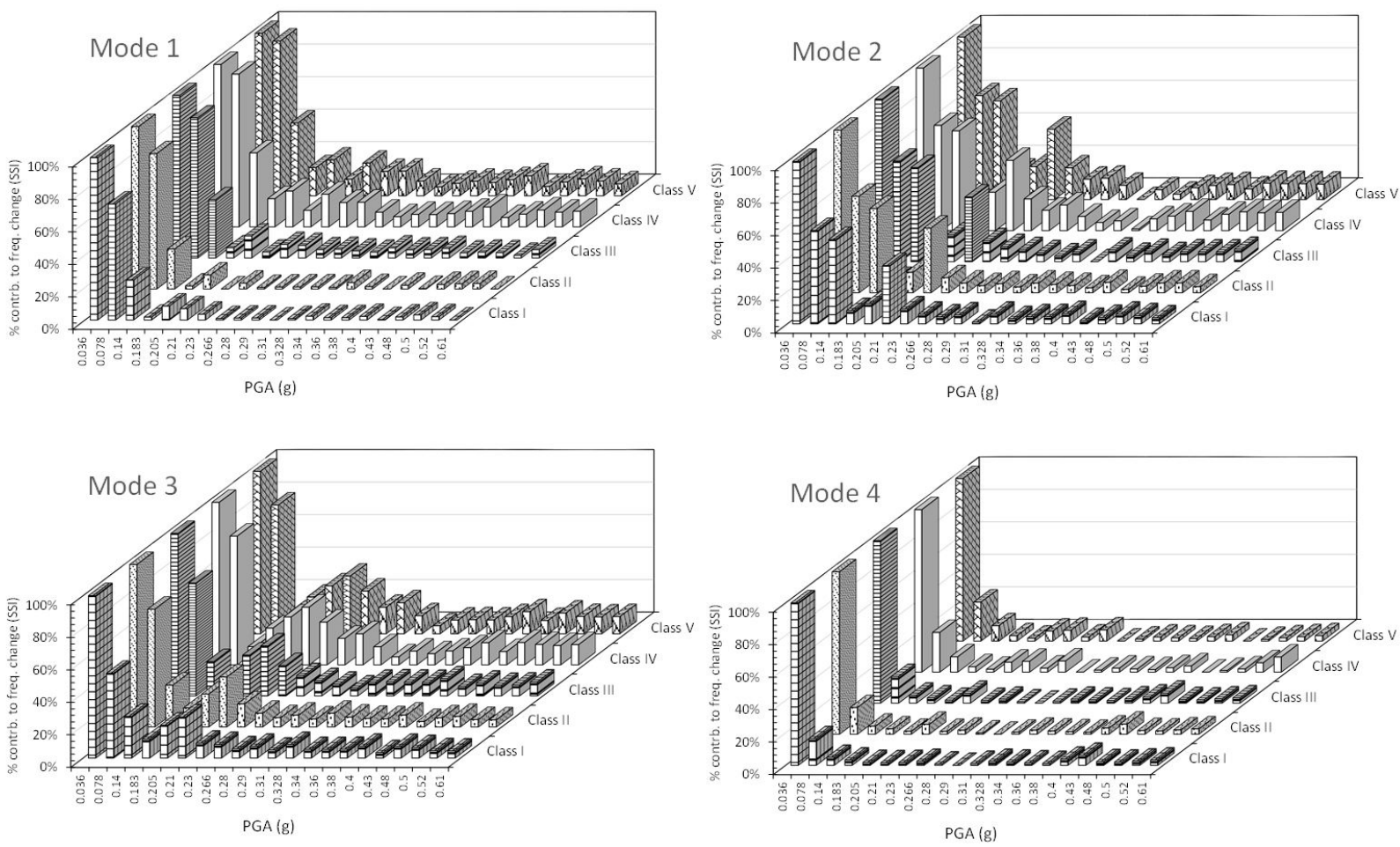

Figure 12: Percentage contribution of SSI towards frequency change - rock profile bridges
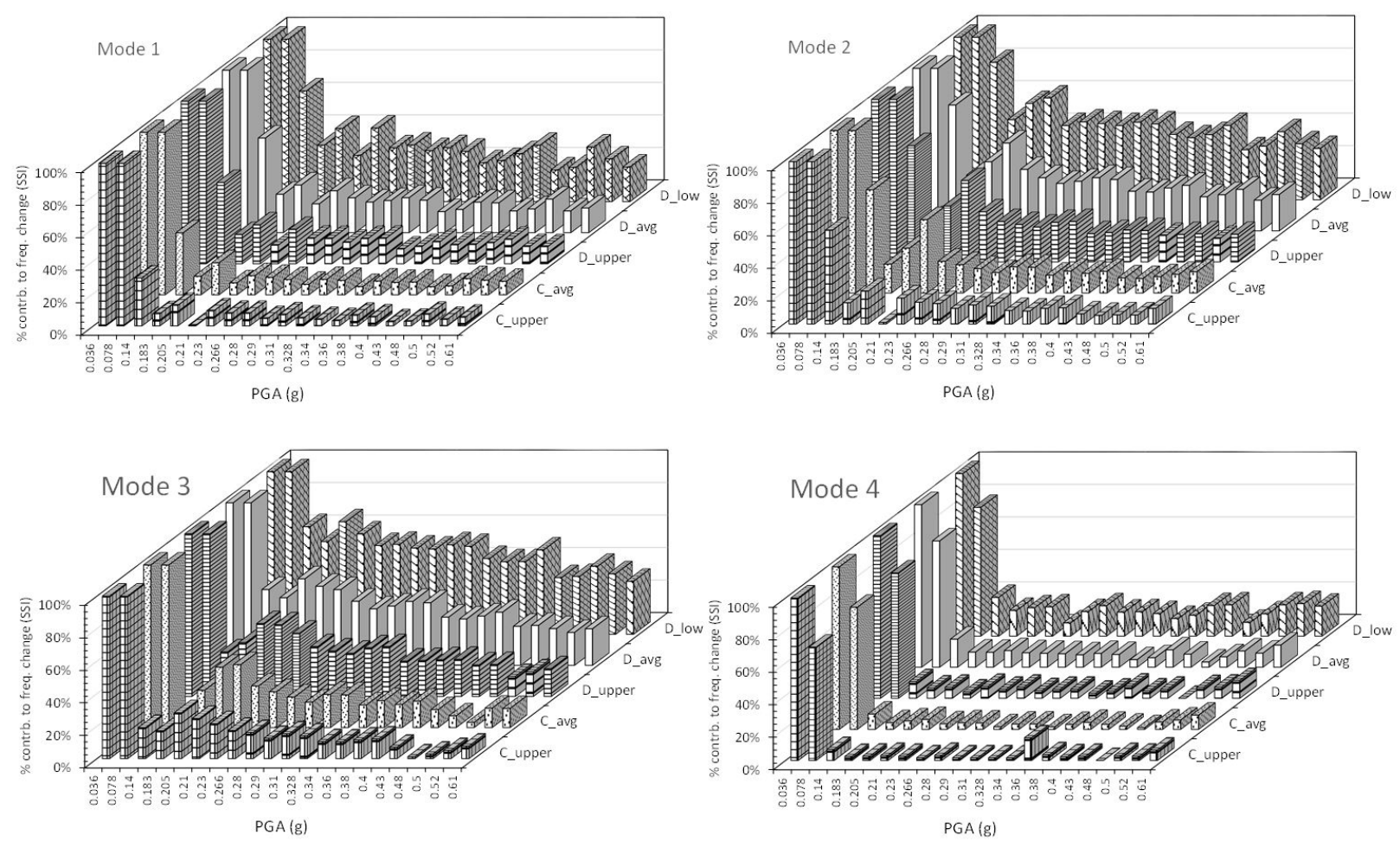

Figure 13: Percentage contribution of SSI towards frequency change - soil profile bridges 


\subsubsection{Reason for higher sensitivity of SSI towards frequency change in DBE motions}

It was interesting to note in Figures 14 and 15 that maximum contribution of SSI towards a modal frequency change occurred for DBE level of seismic intensity. This seemed counter-intuitive, as one would expect more contribution of SSI for higher seismic intensities. This apparent anomaly can be explained by the fact that for low levels of seismic excitations (up to about $0.14 \mathrm{~g}$ ), the pier columns had an effective stiffness of about $80 \%$ which is more than the $70 \%$ limit in AASHTO code for cracked inertia of the pier columns. Therefore, contribution of pier inelasticity towards frequency change was minimal and almost all contribution to frequency change was from SSI for these cases. Therefore, the share of SSI was more for DBE level of seismic intensity.

As level of seismic excitation increased, pier started to enter the inelastic range and its stiffness degraded to as low as $45 \%$ of the initial value as depicted in Figure 7 . There was a corresponding decrease in the soil shear modulus as well for soil profile bridges (Table 4 \& Figure 15) and the soil-foundation stiffness also decreased to as low as $31 \%$ of the initial value. However, the effect of pier stiffness degradation had more significant effect on frequency change than reduction in soil-foundation stiffness, as decreased soil-foundation stiffness was still an order of magnitude higher than the pier column stiffness. Sub-structure stiffness in the bridge system comprised of three components, viz. horizontal and rocking soil-foundation stiffnesses and pier column stiffness. These stiffnesses were arranged in a serial system and the resultant stiffness in such system was dominated by the lowest stiffness; which was the pier column stiffness in this case. This was the reason that changes in modal frequencies were more sensitive to reduction in pier column stiffness than to soilfoundation stiffness for higher levels of seismic intensity.

\subsubsection{Implication for FEM model updating}

Above observation can be utilized in FEM model updating of bridges such that for lower levels of excitations caused by ambient vibrations or weak earthquakes (i.e. acceleration $<0.10 \mathrm{~g}$ ), it will be more fruitful to pay attention to finetuning soil-foundation stiffness as compared to inelastic modeling of pier-column for matching the observed and FEM modal frequencies. An examination of past attempts at FEM model updating supported this observation as well. For example, Panetsos et al. (2010) and Athanatopoulou et al. (2017) utilized $99.29 \%$ and $104 \%$ stiffness of pier columns and $95 \%$ and $93 \%$ of soil-foundation stiffness when matching observed modal frequencies measured under ambient vibrations (about $0.6 \% \mathrm{~g}$ ) for bridges in Italy. Hogan et al. (2012) did a snapback test on a bridge span and employed $94 \%$ of pier column stiffness and $82 \%$ of soil-foundation stiffness to get a good match of FEM predicted frequencies with the ones obtained from the snapback test. However, Arici \& Mosalam (2000) assumed a fixed base (i.e. no SSI) and relied only on changes in pier column stiffness and variation in modal mass to obtain a good match between observed and FEM model frequencies of California bridges under seismic loads. On the other hand, Taciroglu et al. (2014), adjusted pier column stiffness to $50 \%$ and soil-foundation stiffness to $69 \%$ for FEM model updating of Samoa Channel Bridge under Ferndale earthquake $(P G A=0.15 \mathrm{~g})$. Therefore, it can be observed that a lot of variation in updated parameters has been reported and the observation noted earlier in the section should be treated as a general heuristic guideline for FE model updating of a real bridge in addition to engineering judgement and taking into consideration geometry, layout and geotechnical setting of the bridge. 

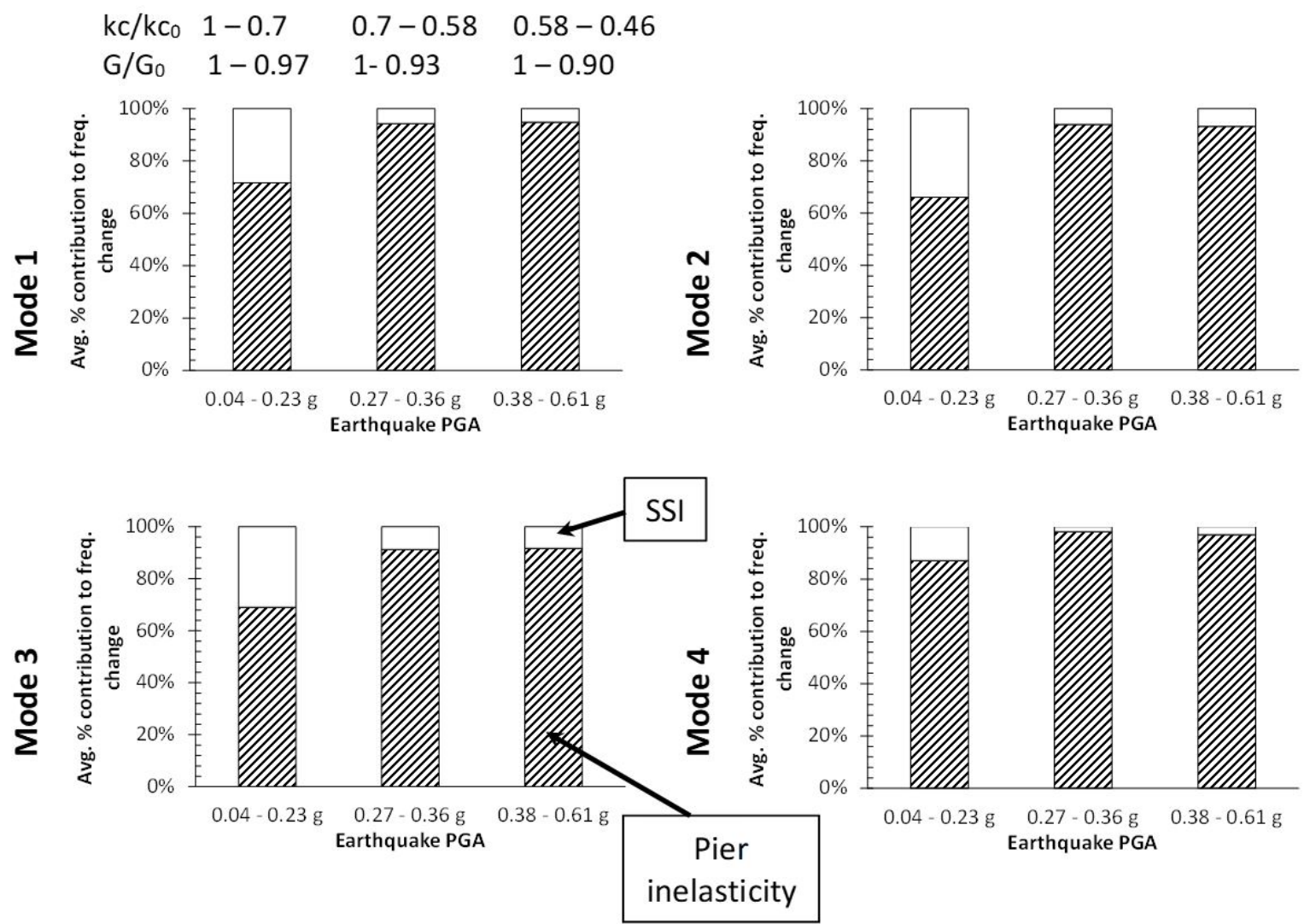

Figure 14: Average percentage contribution to frequency change - rock profile bridges

$\mathrm{kc} / \mathrm{kc}_{0} \quad 1-0.66 \quad 0.66-0.56 \quad 0.56-0.45$

$\mathrm{G} / \mathrm{G}_{0} \quad 0.94-0.49 \quad 0.88-0.41 \quad 0.85-0.31$
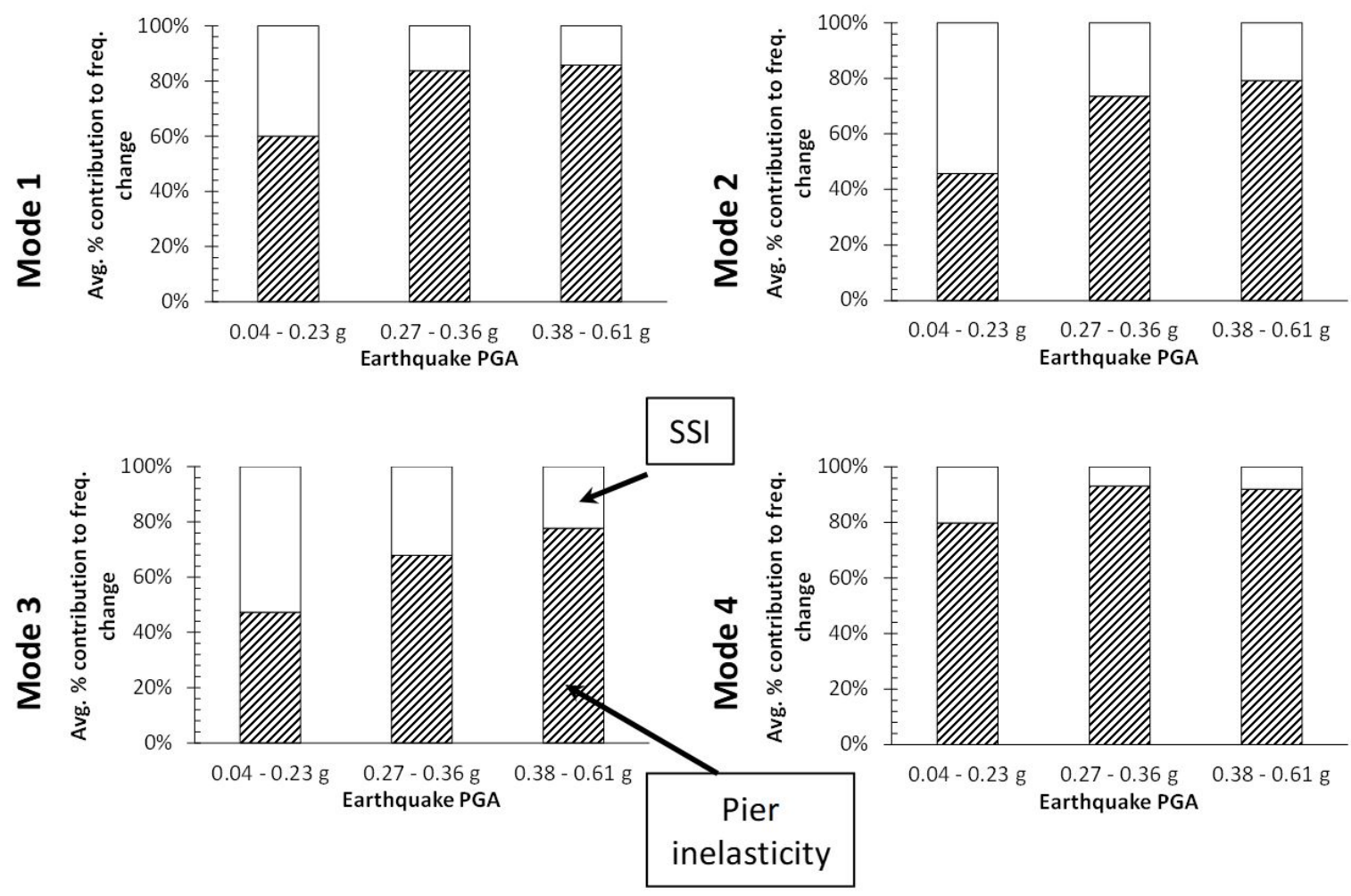

Figure 15: Average percentage contribution to frequency change - soil profile bridges 


\subsubsection{Reason for higher sensitivity of SSI towards changes in the 2 nd and 3rd modal frequencies}

Contribution of SSI towards change in the 2 nd and 3rd modal frequency in both soil profile and rock profile bridges was relatively more as compared to the 1 st and 4th mode as noted in Figures 14 and 15 . This disparity can be attributed to the fact that the 2 nd and $3 r d$ modes were the transverse translation and torsional modes respectively and stiffness of the pier bents in the transverse direction as well as torsional stiffness of the bridge was manifold more than the longitudinal stiffness of the pier columns. It can be appreciated that in a serial spring system of sub-structure stiffness, an increase in pier column stiffness resulted in a decrease in contribution of pier column and a corresponding increase in the share of SSI towards change in modal frequencies. Therefore, in these modes the contribution of SSI was more than the first and the fourth modes. This observation points towards the need of more careful attention to incorporating soil-foundation stiffness in FEM models when attempting to match modal frequencies in the transverse and torsional modes.

\section{MODE SHAPES AND THEIR SENSITIVITY TO SSI AND PIER COLUMN INELASTICITY}

\subsection{Numerically obtained mode shapes}

First six mode shapes of the bridge are depicted in Figure 16. The mode shapes were the same for rock and soil profile bridges. It was noted that modes 1 to 6 were: longitudinal translation, transverse translation, 1st torsion, 1st bending, 2nd bending and 2nd torsion respectively. Modes 3 (1st torsion) and 4 (1st vertical) were switched in some of the analysis cases as listed in Table 6. Change in pier column stiffness was the main reason for switch in the order of these modes. 


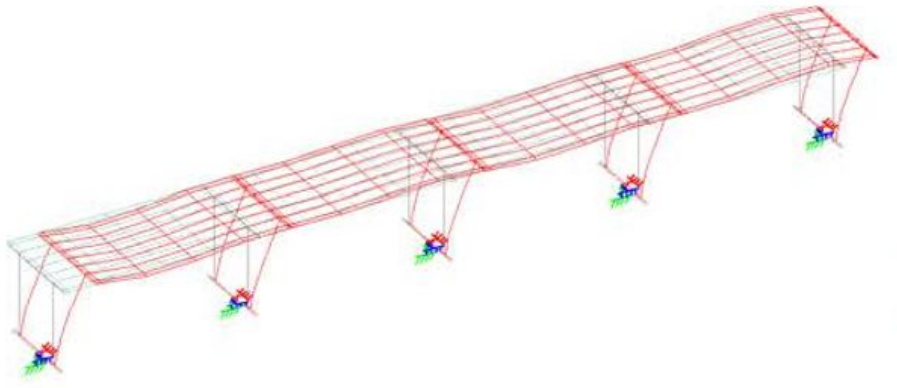

(a) Mode 1 - Longitudinal

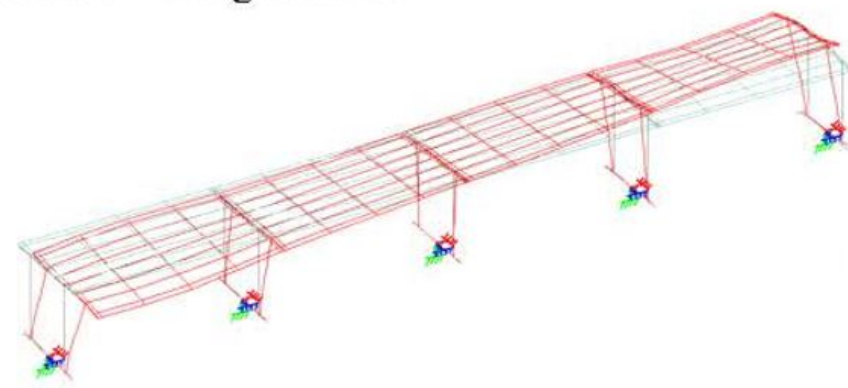

(c) Mode $3^{\mathrm{a}}$ - Torsion 1

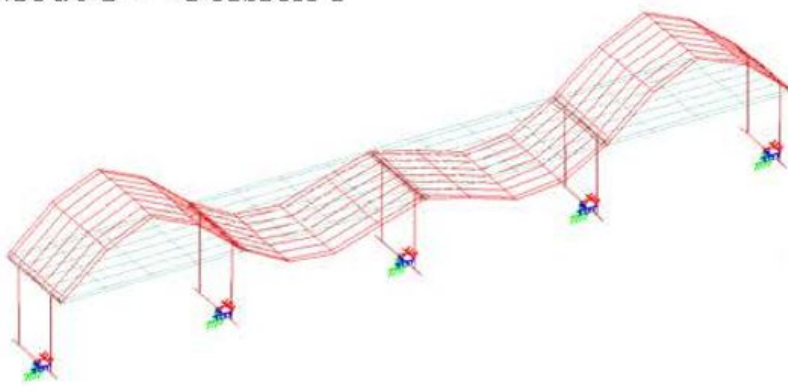

(e) Mode 5 - Bending 2

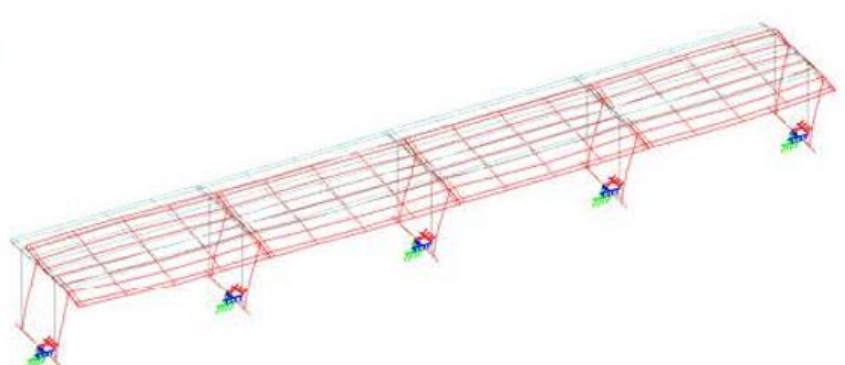

(b) Mode 2 - Transverse

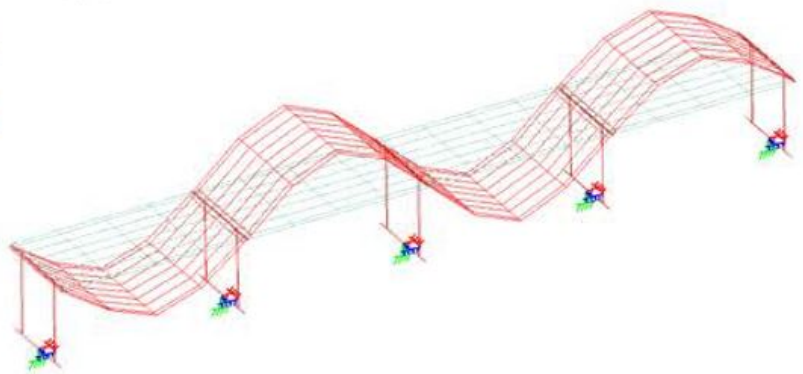

(d) Mode $4^{\mathrm{a}}$ - Bending 1

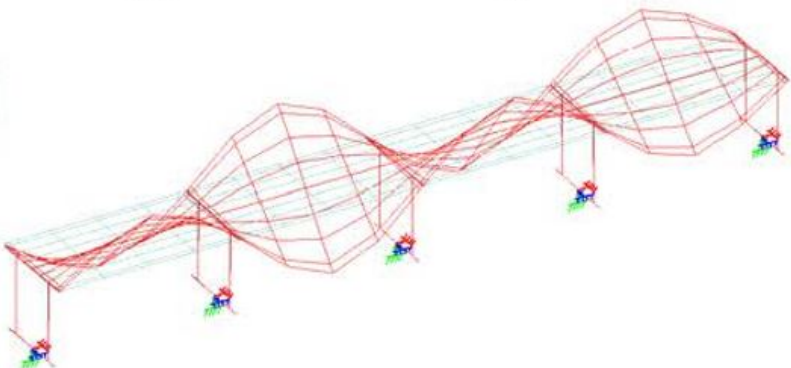

(f) Mode 6-Torsion 2

Figure 16: First six mode shapes of the bridge. ${ }^{a}$ Modes 3 and 4 were switched in some cases - see Table 6

\subsection{Comparison of mode shapes}

Soil profile bridges were selected for this comparison as these bridges exhibited more variation in frequency than the rock profile bridges and effect of SSI and pier inelasticity was also observed to be more pronounced. First six mode shapes for the analysis cases representing different sets of variation in soil-foundation fixity and pier column inelasticity were compared with each other through three commonly used tools in modal analysis, viz. Modal Assurance Criterion (MAC), Coordinate Modal Assurance Criteria (COMAC) and difference in mode shape curvatures.

The considered cases for modal comparison are listed in Table 7. A comparison case comprised of two different scenarios; A and B. Scenario A represented different conditions of pier column inelasticity for a fixed foundation while Scenario B represented various conditions of SSI as well as pier column inelasticity. Modal comparison cases included in both scenarios represented extreme conditions of pier column inelasticity and soil-foundation flexibility in order to exacerbate the differences between the selected scenarios. Case 1 was the example of extreme differences in pier column inelasticity as well as soil-foundation flexibility. Case 2 was similar to Case 1 except for the order of modes 3 and 4 as discussed above (Table 6). Cases 3 and 5 endeavored to find mode shape difference due to the effect of SSI in inelastic and elastic piers respectively. Case 4 was similar to Cases 1 and 2 but the order of pier inelasticity was reversed in Scenarios A and B. Case 6 was included to study the influence of pier inelasticity in a fixed base condition. 
Table 6: Variation in the order of $3^{\text {rd }}$ and $4^{\text {th }}$ mode shapes due to pier inelasticity and boundary conditions

\begin{tabular}{cccccccc}
\hline \multirow{2}{*}{$\begin{array}{c}\text { Pier Inelasticity } \\
\left(\mathbf{k}_{\mathrm{c}} / \mathbf{k}_{\left.\mathrm{c} \_ \text {100 }\right)}\right.\end{array}$} & Fixed & \multicolumn{3}{c}{ SSI with rock-foundation } \\
\cline { 2 - 7 } & & Class I, Class II & Class III, Class IV & Class V & C_upper & C_avg & D_upper, D_avg, D_low \\
\hline $100 \%$ & $\mathrm{~B}$ & $\mathrm{~B}$ & $\mathrm{~B}$ & $\mathrm{~B}$ & $\mathrm{~B}$ & $\mathrm{~B}$ & $\mathrm{~A}$ \\
$98 \%$ & $\mathrm{~B}$ & $\mathrm{~B}$ & $\mathrm{~B}$ & $\mathrm{~B}$ & $\mathrm{~B}$ & $\mathrm{~A}$ & $\mathrm{~A}$ \\
$95 \%$ & $\mathrm{~B}$ & $\mathrm{~B}$ & $\mathrm{~B}$ & $\mathrm{~A}$ & $\mathrm{~A}$ & $\mathrm{~A}$ & $\mathrm{~A}$ \\
$90 \%$ & $\mathrm{~B}$ & $\mathrm{~B}$ & $\mathrm{~A}$ & $\mathrm{~A}$ & $\mathrm{~A}$ & $\mathrm{~A}$ & $\mathrm{~A}$ \\
$85 \%$ & $\mathrm{~A}$ & $\mathrm{~A}$ & $\mathrm{~A}$ & $\mathrm{~A}$ & $\mathrm{~A}$ & $\mathrm{~A}$ & $\mathrm{~A}$ \\
\hline
\end{tabular}

A: $3^{\text {rd }}$ mode $=1^{\text {st }}$ Torsion; $4^{\text {th }}$ mode $=1^{\text {st }}$ vertical; $B: 3^{\text {rd }}$ mode $=1^{\text {st }}$ vertical; $4^{\text {th }}$ mode $=1^{\text {st }}$ Torsion

\subsubsection{Modal Assurance Criteria (MAC) for various cases}

MAC is the most commonly used technique for comparing similarity between mode shapes. MAC values for vectors of mode participation factors $\{\phi\}$ for scenarios A and B were computed form Eq. 18 (Allemang and Brown, 1982):

$\operatorname{MAC}\left(\left\{\phi_{A}\right\}_{i^{\prime}}\left\{\phi_{B}\right\}_{j}\right)=\frac{\left|\left\{\phi_{A}\right\}_{i}^{H}\left\{\phi_{B}^{*}\right\}_{j}\right|^{2}}{\left(\left\{\phi_{A}\right\}_{i}^{H}\left\{\phi_{A}^{*}\right\}_{i}\right)\left(\left\{\phi_{B}\right\}_{j}^{H}\left\{\phi_{B}^{*}\right\}_{j}\right)}$

in which $H$ in the superscript means a Hermitian transpose and ${ }^{*}$ implies complex conjugate, while subscripts $A$ and $B$ refer to scenarios $A$ and $B$ respectively and $i$ and $j$ are the mode indices. MAC values above 0.9 indicates that the modes are strongly related while a value less than 0.05 suggest non-related modes (Ewins, 1984).

Table 7: Cases for computing MAC, COMAC and mode shape curvature difference for various scenarios - soil profile bridges

\begin{tabular}{cccc}
\hline Case No. & Scenario A & Scenario B & Remarks \\
\hline 1 & A1: Fixed base and Elastic pier column & B1: Max. SSI \& max. inelastic pier & Maximum difference due to SSI and \\
pier inelasticity effects.
\end{tabular}

${ }^{1}$ Modes 3 and 4 were switched for this case. ${ }^{2}$ Scenario B3 is the same as A2

Nodes shown in Figure 17 (full model) were used to compute MAC values. Nodes in only one-half of the bridge were included in MAC computations due to symmetry / anti-symmetry of the first six modes as depicted in Figure 16. Selection of nodes for MAC computations was done such that a minimum number of nodes were used and still the first six mode shapes were adequately represented in MAC calculations. Nodes at the foundation and base of the piers were not included as for the fixed base cases, values of mode shape components were zero at these location.

Plots of MAC values for the four cases are shown in Figure 18 while the MAC matrices for these cases are presented in the Appendix Table A2. It was noted that MAC values for the diagonal terms were more than 0.95 for all cases except for Case 1 where modes 3 and 4 were switched. However, in this case, the off-diagonal terms corresponding to the switched modes were greater than 0.95 indicating an excellent correlation between the mode shapes. Modes 2 and 3 (lateral translation and 1st torsion) and modes 4 and 5 (1st and 2 nd vertical) exhibited a fair degree of similarity as MAC vales for these cross modes were between 0.58 and 0.8 .

Values of MAC more than 0.95 for the diagonal terms for the six cases and maximum difference of 0.04 between MAC values of corresponding terms for various cases led to conclude that mode shapes did not show any discernable change as foundation fixity was changed for various soil-foundation conditions and/or decreasing the value of pier 
column stiffness. This implied that comparison of mode shapes through MAC was insensitive to variations due to SSI as well as pier column inelasticity for the bridges studied herein. Therefore, MAC values could not be used as a tool for detecting any change in the soil-foundation boundary condition and/or reduction in pier column stiffness. The difficulty of using MAC values as an indicator of 'damage' or change is well recognized in the literature (Zhang \& Aktan, 1995; Wang et al, 2000; Huth et al., 2005; Chang \& Kim,2016) and was supported by the results of this study as well.

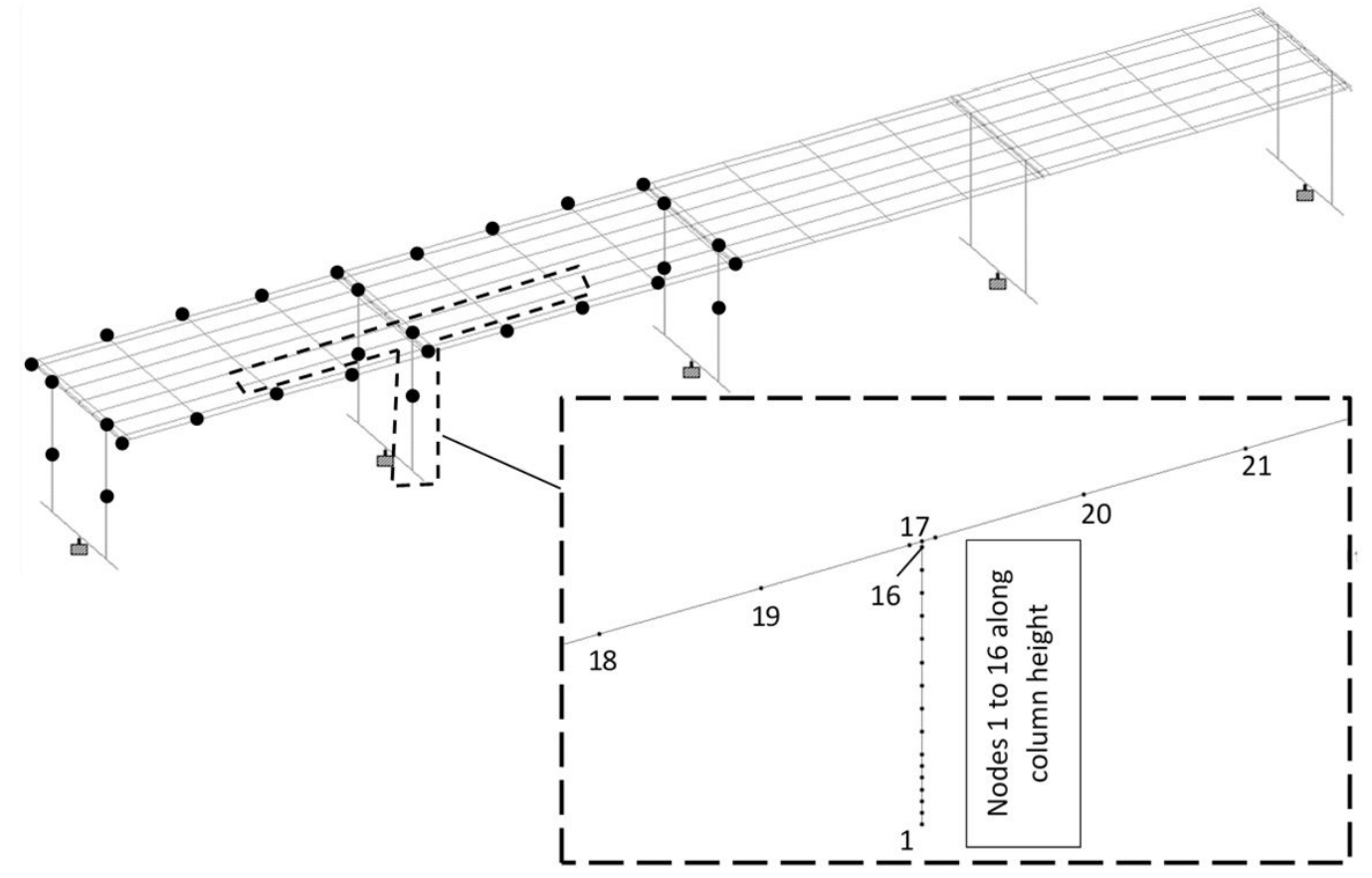

Figure 17: Nodes used in MAC calculations (full model) and for COMAC \& mode shape curvature calculations (inset)

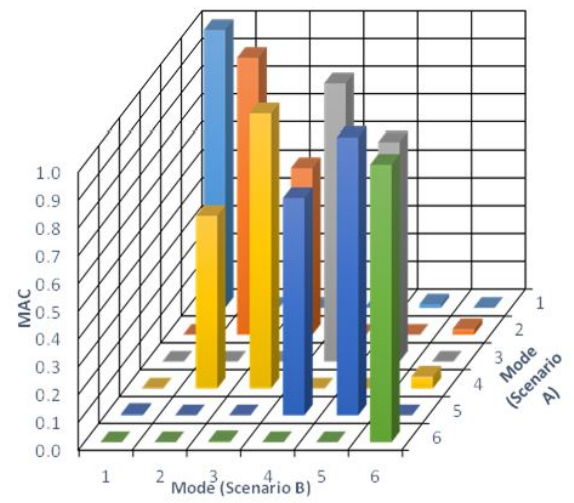

(a) Case 1

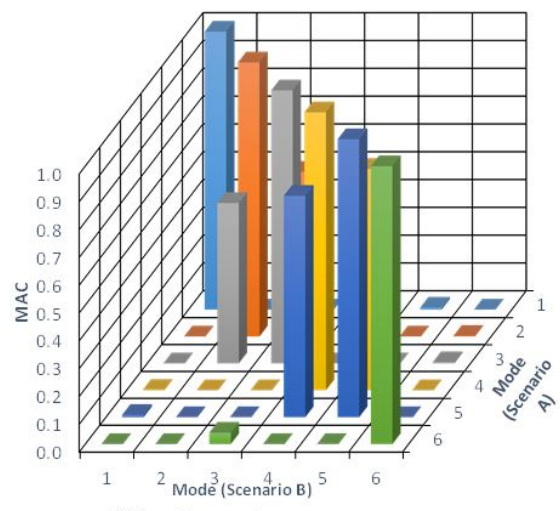

(d) Case 4

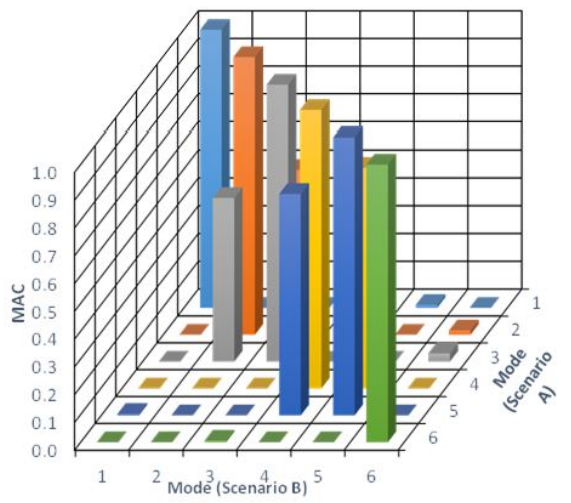

(b) Case 2

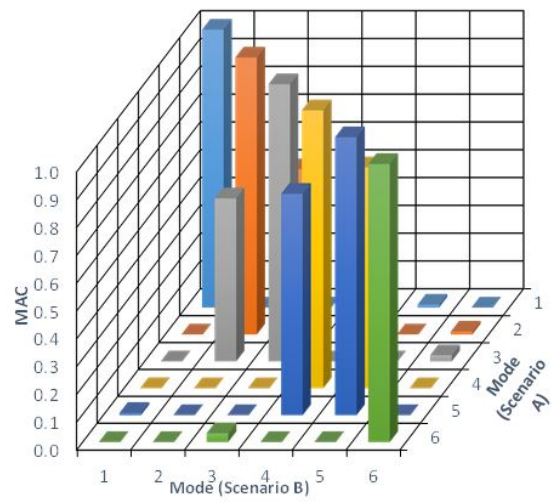

(e) Case 5

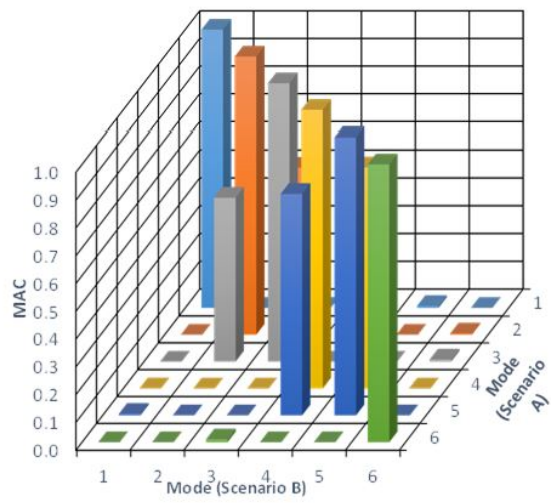

(c) Case 3

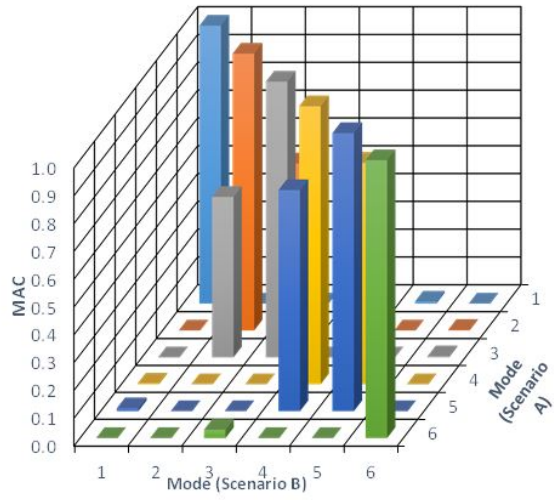

(f) Case 6

Figure 18: Distribution of MAC values for various cases 


\subsubsection{Coordinate Modal Assurance Criteria (COMAC)}

COMAC is one of the location technique to identify the nodes in two mode shape pairs where anomalies in mode shapes could be present. It works similar to MAC but tries to identify difference/similarities in mode shape pairs at a particular node in a given degree of freedom (DOF). In the current study, nodes along the pier columns and few adjacent nodes in the bridge deck were chosen for COMAC calculations as depicted in Figure 17 (inset). COMAC for a particular node along the pier column for a particular degree of freedom was computed using Eq. 19 (Lieven and Ewins, 1988):

$\operatorname{COMAC}(n)=\frac{\left[\sum_{j=1}^{r}\left|\phi_{A}(n, j) \cdot \phi_{B}(n, j)\right|\right]^{2}}{\sum_{j=1}^{r}\left|\phi_{A}(n, j)\right|^{2} \cdot \sum_{j=1}^{r}\left|\phi_{B}(n, j)\right|^{2}}$

where $n$ is the measurement point, $j$ is the mode shape index, $r$ is the number of modes included in COMAC computation and $A \& B$ refers to the two different scenarios of varying soil-foundation fixity and pier column inelasticity.

COMAC values along the pier column nodes and few nodes in the bridge deck were computed for cases $2 \sim 6$ (Table 7 ) for the X-DOF that represented translation along the longitudinal axis of the bridge. COMAC values for Case 1 were not computed as it contained switched 3rd and 4th modes in scenario A1. Table 8 lists the COMAC values for the pier column nodes (\# 1 to 16) and the deck nodes (17 to 21 ) while Figure 19 presents the variation in COMAC values along the pier column height. Except for node \# 1 that was located at the base of the pier column, all other nodes had COMAC values greater than 0.9. COMAC value for node 1 varied between 0.68 (Case 3) and 0.88 (Case 6). Values of COMAC varied between 0.92 and 0.97 for the bottom $2 \mathrm{~m}$ of the pier column. Whereas these values were more than 0.98 for nodes above $2 \mathrm{~m}$ from the base of the pier column and approached unity for nodes located farther from the pier base as well as within the bridge deck.

Variation in COMAC values was noted within the bottom $2 \mathrm{~m}$ of the pier column that was the zone containing the soilfoundation Winkler springs and dashpots as well as the plastic hinge in pier column. Values of COMAC were greater than 0.9, which are considered as almost identical mode shapes in modal testing (Maia and Silva, 1997). However, the relatively small variation in COMAC values (0.92-0.97) in the bottom $2 \mathrm{~m}$ region of the pier column was indicative of relative sensitivity of COMAC to detect changes in modal properties caused by variations in boundary conditions (SSI effect) and/or stiffness of the pier column (pier inelasticity effect). This observation was further verified by computation of mode shape curvatures along the pier column height for various scenarios of boundary conditions and seismic intensity as explained in section 7.2.3.

Table 8: COMAC values for nodes along pier column and in bridge deck for X-DOF (translation along the bridge longitudinal axis)

\begin{tabular}{|c|c|c|c|c|c|c|}
\hline Location & Node \# & Case 2 & Case 3 & Case 4 & Case 5 & Case 6 \\
\hline \multirow{11}{*}{ 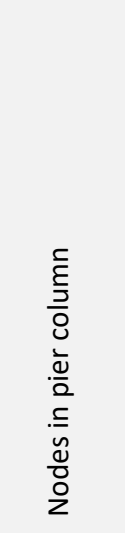 } & 1 & 0.717 & 0.68 & 0.76 & 0.776 & 0.88 \\
\hline & 2 & 0.949 & 0.919 & 0.971 & 0.976 & 0.971 \\
\hline & 3 & 0.969 & 0.932 & 0.985 & 0.983 & 0.991 \\
\hline & 4 & 0.983 & 0.976 & 0.991 & 0.99 & 0.987 \\
\hline & 5 & 0.979 & 0.975 & 0.994 & 0.993 & 0.999 \\
\hline & 6 & 0.988 & 0.99 & 0.991 & 0.996 & 0.992 \\
\hline & 7 & 0.993 & 0.986 & 0.994 & 0.998 & 0.999 \\
\hline & 8 & 0.991 & 0.99 & 0.998 & 0.998 & 0.998 \\
\hline & 9 & 0.992 & 0.992 & 0.998 & 0.998 & 0.997 \\
\hline & 10 & 0.993 & 0.994 & 0.999 & 0.999 & 0.996 \\
\hline & 11 & 0.992 & 0.996 & 1.000 & 0.996 & 0.994 \\
\hline \multirow{10}{*}{ 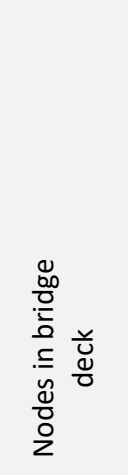 } & 12 & 0.992 & 0.997 & 1.000 & 0.994 & 0.992 \\
\hline & 13 & 0.993 & 0.998 & 1.000 & 0.996 & 0.995 \\
\hline & 14 & 0.997 & 0.999 & 1.000 & 0.998 & 0.999 \\
\hline & 15 & 0.999 & 0.999 & 1.000 & 0.998 & 0.998 \\
\hline & 16 & 0.998 & 1.000 & 1.000 & 0.997 & 0.998 \\
\hline & 17 & 0.998 & 1.000 & 1.000 & 0.999 & 0.997 \\
\hline & 18 & 0.999 & 1.000 & 1.000 & 0.998 & 0.997 \\
\hline & 19 & 1.000 & 1.000 & 1.000 & 0.997 & 0.997 \\
\hline & 20 & 1.000 & 1.000 & 1.000 & 0.999 & 0.999 \\
\hline & 21 & 1.000 & 1.000 & 1.000 & 1.000 & 0.999 \\
\hline
\end{tabular}




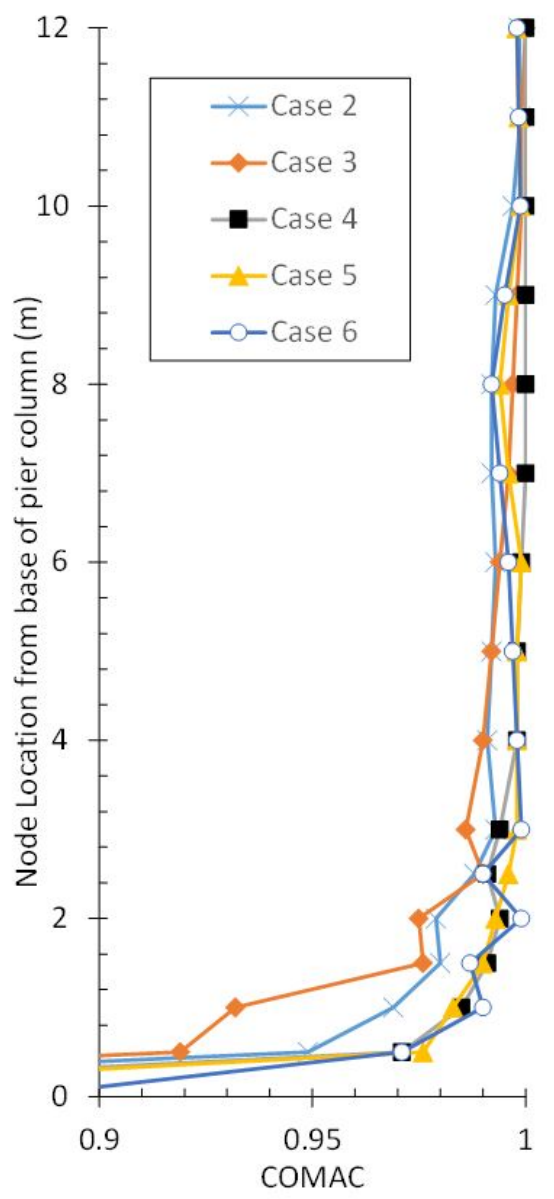

Figure 19: Variation in COMAC for X-DOF (Longitudinal translation) for various cases along pier column height

\subsubsection{Mode shape curvature difference}

Difference in curvatures of displacement mode shapes has been found to be another good indicator for detecting the location causing changes in mode shape pairs. Mode shape curvatures $(\chi)$ are the second differential of displacement mode shapes and are approximated through central differences as given by Eq. 20 (Pandey et al, 1991):

$\chi_{n, j}=\frac{\phi_{n-1, j}-2 \phi_{n, j}+\phi_{n+1, j}}{l^{2}}$

where $n$ is the measurement node, $j$ is the mode shape index and $l$ is the distance between nodes.

Nodes along the column height were located at $1 \mathrm{~m}$ interval except for the bottom $2 \mathrm{~m}$ of the pier column where the interval was $0.5 \mathrm{~m}$. For the end nodes, forward and backward difference approximation was used such that the measurement node index, $n$, was incremented by 1 in Eq. 20 for forward difference and was applied in a reverse order for the backward difference.

Mode shape curvatures were computed for the four scenarios listed in Table 9 for X-DOF in Mode 1 (longitudinal translation) and their variation along the pier height is depicted in Figure 20(a). Mode shape curvatures were the largest at the bottom of pier column and approached zero with increasing height for all scenarios. Difference in mode shape curvatures was calculated for the same cases for which MAC and COMAC values were computed and is depicted in Figure 20(b).

It was noted that MAC values for all cases examined herein were close to unity and COMAC values were greater than 0.9 (meaning no difference in mode shapes for various pairs of scenarios). However, there was a detectable difference in the mode shape curvatures that was especially prominent for nodes in the bottom part of the pier column. As the bottom part of the pier contains the soil-foundation and plastic hinge zones, therefore changes in curvature of mode shapes were detected in this zone as was also noted in the discussion for COMAC values. However, it was difficult to ascertain a trend for relative contribution of SSI and pier column inelasticity to the difference in mode shape curvatures. One would have expected the maximum difference in curvature for case 2; however, curvature difference 
was the largest for cases 4 and 6. Nevertheless, it was concluded that changes in mode shape curvatures were a better indicator for determining the locations where anomalies in structural behavior can be detected through analysis of mode shapes due to changes in boundary conditions or structural inelasticity in the hinge zone.

Table 9: Mode shape curvature values for nodes along pier column height for X-DOF in mode 1

\begin{tabular}{|c|c|c|c|c|}
\hline \multirow{2}{*}{ Node \# } & \multicolumn{4}{|c|}{ Mode shape curvature $\left(\times 10^{-6} \mathrm{~mm}^{-2}\right)$} \\
\hline & Scenario A1 & Scenario B1 & Scenario A3 & Scenario B2 \\
\hline 1 & 0.016 & 0.024 & 0.028 & 0.016 \\
\hline 2 & 0.016 & 0.024 & 0.028 & 0.016 \\
\hline 3 & 0.024 & 0.028 & 0.033 & 0.016 \\
\hline 4 & 0.016 & 0.024 & 0.028 & 0.012 \\
\hline 5 & 0.020 & 0.016 & 0.016 & 0.002 \\
\hline 6 & 0.012 & 0.004 & 0.012 & 0.008 \\
\hline 7 & 0.013 & 0.014 & 0.014 & 0.013 \\
\hline 8 & 0.012 & 0.005 & 0.009 & 0.009 \\
\hline 9 & 0.011 & 0.006 & 0.006 & 0.009 \\
\hline 10 & 0.007 & 0.003 & 0.004 & 0.006 \\
\hline 12 & 0.004 & 0.002 & 0.002 & 0.002 \\
\hline 13 & 0.001 & -0.001 & 0.000 & 0.002 \\
\hline 14 & 0.000 & -0.002 & -0.001 & -0.002 \\
\hline 15 & -0.004 & -0.002 & -0.004 & -0.002 \\
\hline 16 & -0.004 & -0.002 & -0.004 & -0.002 \\
\hline
\end{tabular}
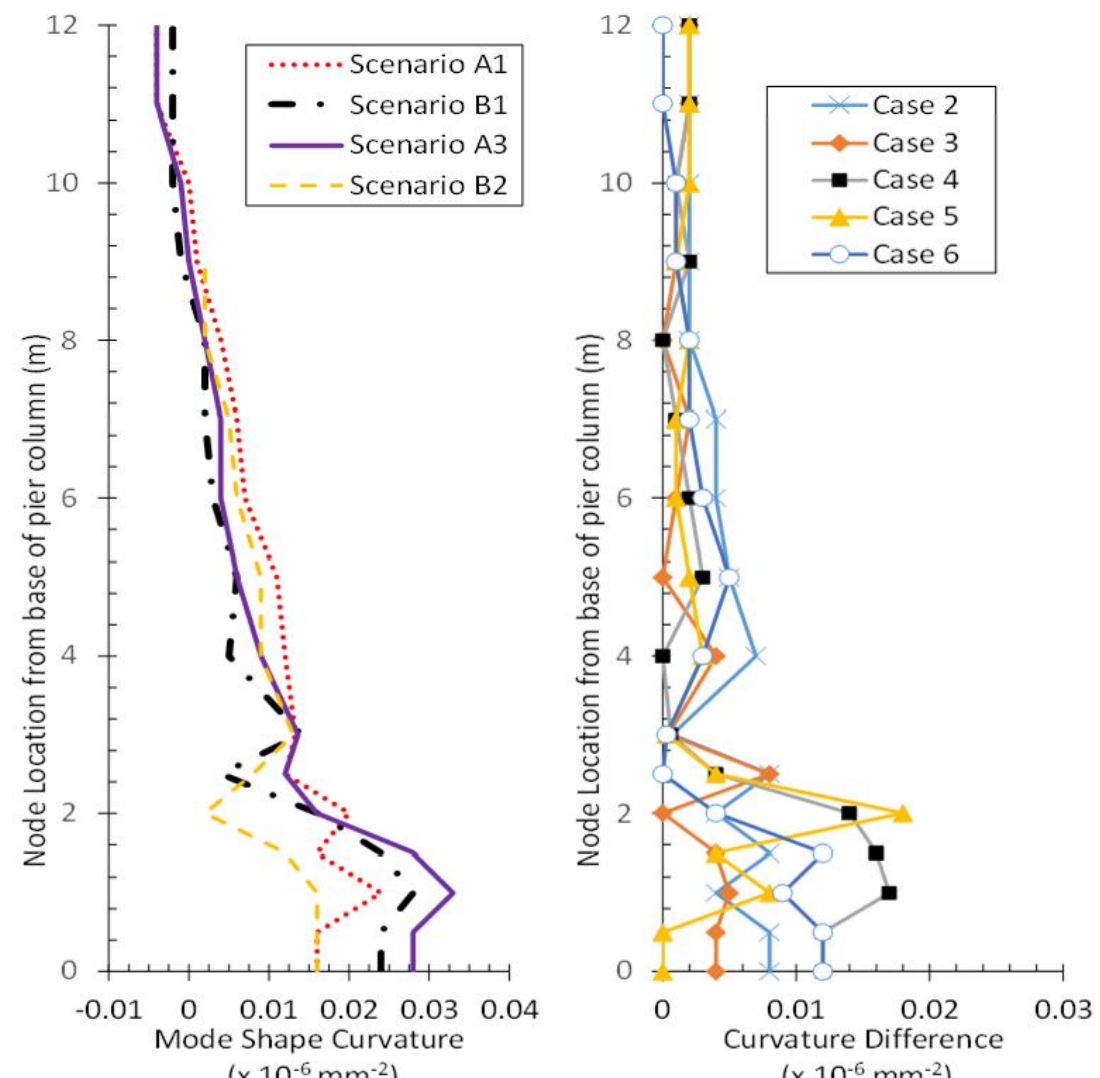

$\left(\times 10^{-6} \mathrm{~mm}^{-2}\right)$

$\left(\times 10^{-6} \mathrm{~mm}^{-2}\right)$

Figure 20: (a) Variation in mode shape curvature, (b) Curvature difference along pier column height for X-DOF in Mode 1 (Longitudinal translation) 


\section{CONCLUSIONS}

The study presented results of more than 450 non-linear dynamic time-history FEM analysis of ordinary multi-span highway bridges founded on shallow foundations in rock profiles and pile-group foundations in soil profiles. Focus of this numerical investigation was to delineate variation in modal frequency and mode shapes of the bridges due to contribution from SSI and pier column inelasticity. It is to be noted that the presented conclusions are specific to the type of bridges studied herein and any generalization to other bridge typologies should be done with proper engineering judgement. Conclusions of the study are summarized as follows:

1. First four modal frequencies showed maximum variation of $5 \%$ and $20 \%$ as compared to the fixed base case for the rock and soil profile bridges respectively when contribution from SSI alone was considered and pier columns were assumed elastic. However, maximum variation in modal frequencies increased to $25 \%$ and $33 \%$ for the rock and soil profile bridges respectively when pier inelasticity effect was also taken into account.

2. Sensitivity of modal frequency change to SSI was the most during DBE level seismic motions for all modes and for both rock and soil profile bridges. Share of SSI decreased for FEE and MCE level seismic motions due to the increasing share of pier-column inelasticity. This observation has a direct implication for FEM model updating such that it will be more effective to fine tune soil-foundation impedance values when matching modal frequencies from FEM model with the recorded values for low levels of seismic excitations (up to $0.10 \mathrm{~g}$ ) and when the level of excitation exceeds this value, the focus should shift to adjusting the pier column stiffness values with less changes done in the soil-foundation impedance values.

3. SSI contribution towards frequency change was observed to be more in the transverse and torsional modes. This implies that for matching transverse and torsional frequencies, more attention should be devoted to adjusting values of soil-foundation impedance in the FEM model updating process.

4. Lower mode shapes were rather insensitive to changes in soil-foundation impedance as well as pier column inelasticity as MAC values were more than 0.95 for all cases of modal pairs investigated herein. This implies that mode shapes comparison is most likely to be less helpful in FEM model updating procedure as compared to frequency changes.

5. COMAC values along the pier column height as well as difference in displacement mode shape curvatures were able to identify the zones where changes in physical state of the pier columns were present due to SSI and pier column inelasticity i.e. the bottom zones of the pier column that included the plastic hinge zone as well as the node containing the soil-foundation Winkler springs and dashpots. However, it was not possible to identify any trend of relative contribution of SSI or pier column inelasticity towards changes in COMAC values or mode shape curvature difference.

6. Modal frequencies were more sensitive to changes in soil-foundation impedance and/or pier column inelasticity as compared to the mode shapes (MAC values), COMAC values or changes in mode shape curvatures. However, through an examination of mode shape curvatures, it was possible to identify the location where changes in the physical parameters of the bridges took place but it was not possible to find a trend of relative sensitivity of this parameter to SSI or pier inelasticity.

\section{ACKNOWLEDGEMENTS}

This work was supported by Kuwait University, Research Grant No. EV01/16.

Editor: Marco L. Bittencourt.

\section{References}

AASHTO (2017). AASHTO LRFD Bridge Design Specifications, 8th edition, American Association of State Highway and Transportation Officials, Washington, DC.

Alampalli, S. (2000). Effects of testing, analysis, damage, and environment on modal parameters. Mechanical Systems and Signal Processing, 14(1), 63-74. 
Allemang, R.J., \& Brown, D.L. (1982, November). A correlation coefficient for modal vector analysis. In Proceedings of the 1st International Modal Analysis Conference (Vol. 1, pp. 110-116). SEM, Orlando.

Arici, Y., \& Mosalam, K. M. (2000, September). System identification and modeling of bridge systems for assessing current design procedures. In Proceedings of SMIP2000 Seminar (pp. 77-95).

ATC-63. (2008). Quantification of Building Seismic Performance Factors. ATC-63 Project Report, prepared by the Applied Technology Council for the Federal Emergency Management Agency, Washington, DC.

Athanatopoulou, A.M., Ekmektsoglou, K., \& Panetsos, P. (2017). Calibration of the dynamic model of a long concrete ravine bridge based on ambient vibration measurements. 16th World Conference on Earthquake Engineering, Santiago, Chile, January 9th to 13th 2017, Paper No. 2217.

Avilés, J., \& Pérez-Rocha, L.E. (2003). Soil-structure interaction in yielding systems. Earthquake Engineering \& Structural dynamics, 32(11), 1749-1771.

Bao, T., \& Liu, Z. (2017). Vibration-based bridge scour detection: a review. Structural Control and Health Monitoring, 24(7), e1937.

Bentz, E. (1999). RESPONSE 2000 - Load-deformation response of reinforced concrete sections. University of Toronto, PhD Dissertation, http://www.ecf.utoronto.ca/ bentz/r2k.htm.

Bieniawski Z.T. (1974). Geomechanics classification of rock masses and its application in tunneling. Proceedings of the 3rd International Congress on Rock Mechanics, ISRM, Denver, 2(2), 27-32.

Boller, C., Chang, F.K., \& Fujino, Y. (Eds.). (2009). Encyclopedia of Structural Health Monitoring. John Wiley and Sons, West Sussex, UK.

Catbas, F.N., \& Aktan, A.E. (2002). Modal analysis for damage identification: past experiences and Swiss Z-24 bridge. In Proceedings of IMAC 20: International Modal Analysis Conference, Los Angeles, CA, pp. 448-456.

Chang, K.C., \& Kim, C.W. (2016). Modal-parameter identification and vibration-based damage detection of a damaged steel truss bridge. Engineering Structures, 122, 156-173.

Chaudhary, M.T.A. (2016). Implication of soil and seismic ground motion variability on dynamic pile group impedance for bridges. Research Project Report \# EV01/15, Kuwait University, Kuwait.

Chaudhary, M.T.A. (2017a). Seismic soil-structure interaction in bridges: Does the answer lie in soil or structure? 16th World Conference on Earthquake Engineering, Santiago, Chile, Paper No. 0157.

Chaudhary, M.T.A. (2017b). Effect of soil-foundation-structure interaction and pier column inelasticity on seismic response of bridges supported on shallow foundations. Australian Journal of Structural Engineering, 17(1), 67-86.

Chaudhary, M.T.A. (2018). Investigation of parameters influencing soil-structure interaction in bridges under seismic loading. Research Project Report \# EV01/16, Kuwait University, Kuwait.

Chaudhary, M.T.A., Abe, M., \& Fujino, Y. (2001). Identification of soil-structure interaction effect in base-isolated bridges from earthquake records. Soil Dynamics and Earthquake Engineering, 21(8), 713-725.

Chaudhary, M.T.A., Abe, M., \& Fujino, Y. (2002). Role of structural details in altering the expected seismic response of baseisolated bridges. Mechanical Systems and Signal Processing, 16(2-3), 413-428.

Chen, X. C., \& Lai, Y. M. (2003). Seismic response of bridge piers on elasto-plastic Winkler foundation allowed to uplift. Journal of Sound and Vibration, 266(5), 957-965.

Chen, X., Omenzetter, P., \& Beskhyroun, S. (2014, July). Calibration of the finite element model of a twelve-span prestressed concrete bridge using ambient vibration data. In Proceedings of the 7th European Workshop on Structural Health Monitoring, Nantes, France.

Ciampoli, M., \& Pinto, P.E. (1995). Effects of soil-structure interaction on inelastic seismic response of bridge piers. Journal of Structural Engineering, 121(5), 806-814.

Collins, M.P. and Mitchell, D. (1991). Prestressed Concrete Structures, Prentice Hall, New Jersey, 766 pp.

Costa, C., Ribeiro, D., Jorge, P., Silva, R., Arêde, A., \& Calçada, R. (2016). Calibration of the numerical model of a stone masonry railway bridge based on experimentally identified modal parameters. Engineering Structures, 123, 354-371. 
CSI (2019). SAP2000 - Linear and nonlinear static and dynamic analysis and design of three-dimensional structures: Basic Analysis Reference Manual. Computers and Structures, Inc., Berkeley, California.

Dilena, M., \& Morassi, A. (2011). Dynamic testing of a damaged bridge. Mechanical Systems and Signal Processing, 25(5), 1485-1507.

Dobry, R. and Gazetas, G. (1988). Simple method for dynamic stiffness and damping of floating pile groups. Geotechnique, 38(4), 557-574.

Ewins, D. J. (1984). Modal Testing: Theory and Practice. Research Studies Press, Somerset, UK.

Fan, W., \& Qiao, P. (2011). Vibration-based damage identification methods: a review and comparative study. Structural Health Monitoring, 10(1), 83-111.

Faraonis, P., Sextos, A., Papadimitriou, C., Chatzi, E., \& Panetsos, P. (2019). Implications of subsoil-foundation modelling on the dynamic characteristics of a monitored bridge. Structure and Infrastructure Engineering, 15(2), 180-192.

Fraino, M., Ventura, C.E., Liam Finn, W.D., \& Taiebat, M. (2012, September). Seismic soil-structure interaction effects in instrumented bridges. In Proceedings of the 15th World Conference on Earthquake Engineering (pp. 1-10). Portuguese Association for Earthquake Engineering.

Friswell, M., \& Mottershead, J.E. (2013). Finite element model updating in structural dynamics (Vol. 38). Springer.

Gazetas, G. (1984). Seismic response of end-bearing piles. Soil Dynamics and Earthquake Engineering, 3(2), 82-93.

Gazetas, G. and Dobry, R. (1984). Horizontal response of piles in layered soils. Journal of Geotechnical Engineering, ASCE, 110(1), 20-40.

Gomez, H.C., Ulusoy, H.S., \& Feng, M.Q. (2013). Variation of modal parameters of a highway bridge extracted from six earthquake records. Earthquake Engineering \& Structural Dynamics, 42(4), 565-579.

Grange, S., Botrugno, L., Kotronis, P., \& Tamagnini, C. (2011). The effects of soil-structure interaction on a reinforced concrete viaduct. Earthquake Engineering \& Structural Dynamics, 40(1), 93-105.

Hogan, L.S., \& Wotherspoon, L.M. (2014). Assessment of soil-structure interaction methods using full scale dynamic testing, 2014 NZSEE Conference, Auckland, NZ, paper O18.

Hogan, L.S., Wotherspoon, L.M., Beskhyroun, S., \& Ingham, J.M. (2012, September). Vibration testing of an in situ bridge pier to determine soil-structure interaction effects. 15th World Conference on Earthquake Engineering, Lisbon.

Huth, O., Feltrin, G., Maeck, J., Kilic, N., \& Motavalli, M. (2005). Damage identification using modal data: Experiences on a prestressed concrete bridge. Journal of Structural Engineering, 131(12), 1898-1910.

Jeremić, B., Kunnath, S., \& Xiong, F. (2004). Influence of soil-foundation-structure interaction on seismic response of the I-880 viaduct. Engineering Structures, 26(3), 391-402.

Ju, S.H. (2013). Determination of scoured bridge natural frequencies with soil-structure interaction. Soil Dynamics and Earthquake Engineering, 55, 247-254.

Kalkan, E., \& Kwong, N.S. (2011). Assessment of modal-pushover-based scaling procedure for nonlinear response history analysis of ordinary standard bridges. Journal of Bridge Engineering, 17(2), 272-288.

Kappos, A.J., \& Sextos, A.G. (2009). Seismic assessment of bridges accounting for nonlinear material and soil response, and varying boundary conditions. In: Coupled site and soil-structure interaction effects with application to seismic risk mitigation (pp. 195-208). Springer, Dordrecht.

Katsanos, E.I., Sextos, A.G. \& Manolis, G.D. (2010). Selection of earthquake ground motion records: A state-of-the-art review from a structural engineering perspective. Soil Dynamics and Earthquake Engineering, 30(4), 157-169.

Kawashima, K. (1980). Soil-structure interaction of a highway bridge with use of recorded strong-motion accelerations. 7th World Conference on Earthquake Engineering, Vol. 6, pp. 81-88, Istanbul, Turkey.

Lesgidis, N., Sextos, A., \& Kwon, O.S. (2017). Influence of frequency-dependent soil-structure interaction on the fragility of R/C bridges. Earthquake Engineering \& Structural Dynamics, 46(1), 139-158.

Lieven, N.A.J., \& Ewins, D.J. (1988, February). Spatial correlation of mode shapes, the coordinate modal assurance criterion (COMAC). Proceedings of the Sixth International Modal Analysis Conference, Kissimmee, Florida, Vol. 1, pp. 690-695. 
Lombardi, D., \& Bhattacharya, S. (2014). Modal analysis of pile-supported structures during seismic liquefaction. Earthquake Engineering \& Structural Dynamics, 43(1), 119-138.

Maalek, S., Akbari, R., \& Ziaei-Rad, S. (2010). The effects of the repair operations and replacement of the elastomeric bearings on the modal characteristics of a highway bridge. Structure and Infrastructure Engineering, 6(6), 753-765.

Maia, N.M.M., \& e Silva, J.M.M. (1997). Theoretical and experimental modal analysis. Research Studies Press, Somerset, UK.

Makris, N. and Gazetas, G. (1992). Dynamic pile-soil-pile interaction. Part II: Lateral and seismic response. Earthquake Engineering \& Structural Dynamics, 21, 145-162.

Makris, N., Cardosa, J., Badoni, D., and Delis, E. (1993). Soil-pile group-superstructure interaction in applications of seismic analysis of bridges. Report NDCE 93-001, University of Notre Dame, USA.

Martakis, P., Taeseri, D., Chatzi, E., \& Laue, J. (2017). A centrifuge-based experimental verification of Soil-Structure Interaction effects. Soil Dynamics and Earthquake Engineering, 103, 1-14.

Moughty, J.J., \& Casas, J.R. (2017). A state of the art review of modal-based damage detection in bridges: Development, challenges, and solutions. Applied Sciences, 7(5), 510.

Mylonakis, G. \& Gazetas, G. (2000). Seismic soil-structure interaction: beneficial or detrimental? Journal of Earthquake Engineering, 4(3), 277-301.

Mylonakis, G., Syngros, C., Gazetas, G., \& Tazoh, T. (2006a). The role of soil in the collapse of 18 piers of Hanshin Expressway in the Kobe earthquake. Earthquake Engineering \& Structural Dynamics, 35(5), 547-575.

Mylonakis, G., Nikolaou, S., \& Gazetas, G. (2006b). Footings under seismic loading: Analysis and design issues with emphasis on bridge foundations. Soil Dynamics and Earthquake Engineering, 26(9), 824-853.

Ni, P., Petrini, L., \& Paolucci, R. (2014). Direct displacement-based assessment with nonlinear soil-structure interaction for multi-span reinforced concrete bridges. Structure and Infrastructure Engineering, 10(9), 1211-1227.

NIST (2012). Soil-structure interaction for building structures, NIST GCR 12-917-21, National Institute of Standards and Technology, Gaithersburg, MD.

Ntotsios, E., Karakostas, C., Lekidis, V., Panetsos, P., Nikolaou, I., Papadimitriou, C., \& Salonikos, T. (2009). Structural identification of Egnatia Odos bridges based on ambient and earthquake induced vibrations. Bulletin of Earthquake Engineering, 7(2), 485.

Ouanani, M., \& Tiliouine, B. (2015). Effects of foundation soil stiffness on the 3-D modal characteristics and seismic response of a highway bridge. KSCE Journal of Civil Engineering, 19(4), 1009-1023.

Pandey, A.K., Biswas, M., \& Samman, M.M. (1991). Damage detection from changes in curvature mode shapes. Journal of sound and vibration, 145(2), 321-332.

Panetsos, P., Ntotsios, E., Papadimitriou, C., Papadioti, D.C. and Dakoulas, P. (2010). Health monitoring of Metsovo Bridge using ambient vibrations. In: Casciati, F. and Giordano, M. (eds). Structural Health Monitoring 2010: Proceedings of the 5th European Workshop on Structural Health Monitoring, 28th June-4th July 2010, Sorrento, Italy, pp. 1081 -1088.

Papadopoulos, M., Van Beeumen, R., François, S., Degrande, G., \& Lombaert, G. (2018). Modal characteristics of structures considering dynamic soil-structure interaction effects. Soil Dynamics and Earthquake Engineering, 105, 114-118.

Paulay, T. and Priestley, M.J.N. (1992). Seismic Design of Reinforced Concrete and Masonry Buildings, John Wiley and Sons, New York, $767 \mathrm{pp}$

PEER NGA-West2 (2018). PEER ground motion database, Pacific Center for Earthquake Engineering Research, Berkeley, CA. http://ngawest2.berkeley.edu/

Pitilakis, D., Dietz, M., Wood, D.M., Clouteau, D., \& Modaressi, A. (2008). Numerical simulation of dynamic soil-structure interaction in shaking table testing. Soil Dynamics and Earthquake Engineering, 28(6), 453-467.

Reese, L.C., Cooley, L.A., \& Radhakrishnan, N. (1984). Laterally Loaded Piles and Computer Program COM624G. University of Texas at Austin.

Şadan, O.B., Petrini, L., \& Calvi, G.M. (2013). Direct displacement-based seismic assessment procedure for multi-span reinforced concrete bridges with single-column piers. Earthquake Engineering \& Structural Dynamics, 42(7), $1031-1051$. 
Salawu, O.S. (1997). Detection of structural damage through changes in frequency: a review. Engineering Structures, 19(9), 718-723.

Sextos, A., Faraonis, P., Zabel, V., Wuttke, F., Arndt, T., \& Panetsos, P. (2016). Soil-bridge system stiffness identification through field and laboratory measurements. Journal of Bridge Engineering, 21(10), 04016062.

Sextos, A.G., Kappos, A.J., \& Pitilakis, K.D. (2003). Inelastic dynamic analysis of RC bridges accounting for spatial variability of ground motion, site effects and soil-structure interaction phenomena. Part 2: Parametric study. Earthquake Engineering \& Structural Dynamics, 32(4), 629-652.

Spyrakos, C.C. (1990). Assessment of SSI on the longitudinal seismic response of short span bridges. Engineering Structures, 12(1), 60-66.

Taciroglu, E., Shamsabadi, A., Abazarsa, F., Nigbor, R.L. and Ghahari, S.F. (2014). Comparative Study of Model Predictions and Data from Caltrans/CSMIP Bridge Instrumentation Program: A Case study on the Eureka-Samoa Channel Bridge, Report No. CA14-2418, UCLA-SGEL Report No. 2014-01, University of California, LA.

Teughels, A., \& De Roeck, G. (2004). Structural damage identification of the highway bridge Z24 by FE model updating. Journal of Sound and Vibration, 278(3), 589-610.

Thorenfeldt, E., Tomaszewicz, A. and Jensen, J.J. (1987). Mechanical properties of high-strength concrete and application in design. Proceedings of the Symposium “Utilization of High Strength Concrete”, Stavanger, Norway, pp. 149-159.

Vecchio, F.J. and Collins, M.P. (1986). The modified compression field theory for reinforced concrete elements subjected to shear. ACl Journal, 83(2), 219-231.

Vlassis, A.G., \& Spyrakos, C.C. (2001). Seismically isolated bridge piers on shallow soil stratum with soil-structure interaction. Computers \& Structures, 79(32), 2847-2861.

Wang, J.Y., Ko, J.M., \& Ni, Y.Q. (2000, June). Modal sensitivity analysis of Tsing Ma Bridge for structural damage detection. In: Proceedings of Nondestructive Evaluation of Highways, Utilities, and Pipelines IV, Newport Beach, CA, Vol. 3995, pp. 300-311, SPIE -The International Society for Optics and Photonics.

Wolf, J.P. (1985). Soil-structure interaction. Prentice Hall Inc., Englewood Cliffs, New Jersey ISBN 0 I3, 221565(9), 01.

Xia, Y., Chen, B., Weng, S., Ni, Y.Q., \& Xu, Y.L. (2012). Temperature effect on vibration properties of civil structures: a literature review and case studies. Journal of Civil Structural Health Monitoring, 2(1), 29-46.

Zhang, J., \& Tang, Y. (2006). Evaluating radiation damping of shallow foundations on nonlinear soil medium for soil-structure interaction analysis of bridges. In US-Japan Bridge Engineering Workshop, Seattle, WA.

Zhang, Z., \& Aktan, A.E. (1995, February). The damage indices for the constructed facilities. In: Proceedings of $13^{\text {th }}$ International Modal Analysis Conference, Nashville, TN, Vol. 13, pp. 1520-1529.

Zheng, Y., Chen, B., \& Chen, W. (2015). Elasto-plastic seismic response of RC continuous bridge with foundation-pier dynamic interaction. Advances in Structural Engineering, 18(6), 817-836. 


\section{APPENDIX}

Appendix contains two tables. Table A1 lists the ground motions used in the study while Table A2 presents the values of MAC for the six cases investigated in the study.

Table A1: Ground motions used in the study

\begin{tabular}{|c|c|c|c|c|c|c|c|c|}
\hline \multicolumn{2}{|c|}{ EQ Record ID } & \multirow{2}{*}{$\begin{array}{c}\text { Seismic event } \\
\text { Edgecombe, NZ }\end{array}$} & \multirow{2}{*}{$\frac{\text { Year }}{1987}$} & Station & \multirow{2}{*}{$\frac{\text { Magnitude }}{6.6}$} & \multirow{2}{*}{$\begin{array}{c}\text { PGA (g) } \\
0.036\end{array}$} & \multirow{2}{*}{ 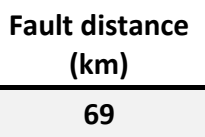 } & \multirow{2}{*}{$\frac{V_{s}(m / s)}{425}$} \\
\hline \multirow{7}{*}{ 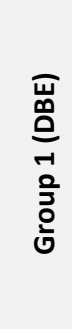 } & 1 & & & Maraenui Primary School & & & & \\
\hline & 2 & Oroville-04 & 1975 & Medical Center & 4.37 & 0.078 & 9.2 & 519 \\
\hline & 3 & Irpinia, Italy & 1980 & Calitri & 6.9 & 0.14 & 17 & 600 \\
\hline & 4 & Chi-Chi, Taiwan & 1999 & CHY015 & 7.6 & 0.183 & 38.1 & 229 \\
\hline & 5 & Spitak- Armenia & 1988 & Gukasian & 6.77 & 0.205 & 24 & 275 \\
\hline & 6 & Kobe, Japan & 1995 & Shin Osaka & 6.9 & 0.21 & 19 & 256 \\
\hline & 7 & Kocaeli, Turkey & 1999 & Ambarli & 7.51 & 0.23 & 69.6 & 175 \\
\hline \multirow{7}{*}{ 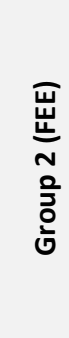 } & 8 & San Fernando & 1971 & Castaic - Old Ridge Route & 6.61 & 0.266 & 23 & 450 \\
\hline & 9 & Landers & 1992 & Joshua Tree & 7.28 & 0.28 & 11 & 379 \\
\hline & 10 & Morgan Hill & 1984 & Gilroy Array \#6, 90 & 6.19 & 0.29 & 10 & 663 \\
\hline & 11 & Superstition Hills & 1987 & Poe Road (temp) & 6.5 & 0.31 & 11.7 & 208 \\
\hline & 12 & Tabas, Iran & 1978 & Dayhook & 7.35 & 0.328 & 13.9 & 660 \\
\hline & 13 & Hector Mine & 1999 & Hector & 7.1 & 0.34 & 12 & 685 \\
\hline & 14 & Imperial Valley & 1979 & Elcentro Array \#11 & 6.5 & 0.36 & 13.5 & 196 \\
\hline \multirow{7}{*}{ 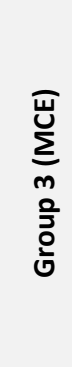 } & 15 & Cape Mendocino & 1992 & Rio Dell Overpass - FF & 7.0 & 0.38 & 13 & 312 \\
\hline & 16 & Loma Prieta & 1989 & Gilroy Array \#2 & 6.93 & 0.40 & 11 & 271 \\
\hline & 17 & Northridge-01 & 1994 & Beverly Hills - 14145 Mulhol & 6.69 & 0.43 & 17 & 356 \\
\hline & 18 & Kobe, Japan & 1995 & Nishi Akashi, 0 & 6.9 & 0.48 & 9 & 609 \\
\hline & 19 & Manjil, Iran & 1990 & Abbar & 7.4 & 0.50 & 13 & 724 \\
\hline & 20 & Duzce, Turkey & 1999 & Duzce & 7.14 & 0.52 & 6.6 & 276 \\
\hline & 21 & Loma Prieta & 1989 & Gilroy Array \#3 & 6.93 & $\begin{array}{c}0.61 \\
(0.56)\end{array}$ & 12.8 & 350 \\
\hline
\end{tabular}

Values in parenthesis are the recorded ones.

Table A2: MAC values for six cases

(i) Case 1

\begin{tabular}{|c|c|c|c|c|c|c|c|c|}
\hline & \multicolumn{8}{|c|}{ Scenario B } \\
\hline & Mode & & 1 & 2 & 3 & 4 & 5 & 6 \\
\hline \multirow{7}{*}{ 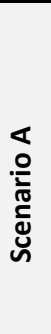 } & & $f(H z)$ & 1.179 & 1.496 & 1.598 & 2.142 & 2.382 & 2.664 \\
\hline & 1 & 1.654 & 0.998 & 0.000 & 0.000 & 0.004 & 0.012 & 0.000 \\
\hline & 2 & 2.167 & 0.000 & 0.994 & 0.600 & 0.000 & 0.000 & 0.021 \\
\hline & 3 & 2.233 & 0.000 & 0.000 & 0.000 & 0.999 & 0.789 & 0.000 \\
\hline & 4 & 2.321 & 0.000 & 0.622 & 0.987 & 0.000 & 0.000 & 0.043 \\
\hline & 5 & 2.493 & 0.006 & 0.000 & 0.000 & 0.782 & 0.999 & 0.000 \\
\hline & 6 & 2.719 & 0.000 & 0.000 & 0.004 & 0.000 & 0.000 & 0.998 \\
\hline
\end{tabular}


(ii) Case 2

\begin{tabular}{|c|c|c|c|c|c|c|c|c|}
\hline & \multicolumn{8}{|c|}{ Scenario B } \\
\hline & Mode & & 1 & 2 & 3 & 4 & 5 & 6 \\
\hline \multirow{7}{*}{ 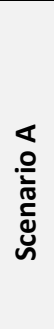 } & & $f(H z)$ & 1.179 & 1.496 & 1.598 & 2.142 & 2.382 & 2.664 \\
\hline & 1 & 1.568 & 0.999 & 0.000 & 0.000 & 0.003 & 0.010 & 0.000 \\
\hline & 2 & 2.101 & 0.000 & 0.997 & 0.594 & 0.000 & 0.000 & 0.015 \\
\hline & 3 & 2.106 & 0.000 & 0.589 & 0.994 & 0.000 & 0.000 & 0.030 \\
\hline & 4 & 2.225 & 0.000 & 0.000 & 0.000 & 0.999 & 0.794 & 0.000 \\
\hline & 5 & 2.481 & 0.006 & 0.000 & 0.000 & 0.797 & 0.999 & 0.000 \\
\hline & 6 & 2.713 & 0.000 & 0.000 & 0.006 & 0.000 & 0.000 & 0.999 \\
\hline
\end{tabular}

(iii) Case 3

\begin{tabular}{|c|c|c|c|c|c|c|c|c|}
\hline & \multicolumn{8}{|c|}{ Scenario B } \\
\hline & Mode & & 1 & 2 & 3 & 4 & 5 & 6 \\
\hline \multirow{7}{*}{ 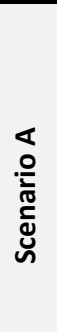 } & & $f(H z)$ & 1.179 & 1.496 & 1.598 & 2.142 & 2.382 & 2.664 \\
\hline & 1 & 1.280 & 1.000 & 0.000 & 0.000 & 0.001 & 0.007 & 0.000 \\
\hline & 2 & 1.812 & 0.000 & 0.989 & 0.601 & 0.000 & 0.000 & 0.005 \\
\hline & 3 & 1.995 & 0.000 & 0.590 & 0.992 & 0.000 & 0.000 & 0.008 \\
\hline & 4 & 2.175 & 0.000 & 0.000 & 0.000 & 1.000 & 0.796 & 0.000 \\
\hline & 5 & 2.431 & 0.006 & 0.000 & 0.000 & 0.797 & 0.999 & 0.000 \\
\hline & 6 & 2.687 & 0.000 & 0.000 & 0.010 & 0.000 & 0.000 & 1.000 \\
\hline
\end{tabular}

(iv) Case 4

\begin{tabular}{|c|c|c|c|c|c|c|c|c|}
\hline & \multicolumn{8}{|c|}{ Scenario B } \\
\hline & Mode & & 1 & 2 & 3 & 4 & 5 & 6 \\
\hline \multirow{7}{*}{ 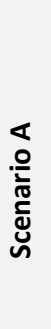 } & & $f(H z)$ & 1.515 & 1.869 & 2.233 & 2.321 & 2.493 & 2.717 \\
\hline & 1 & 1.280 & 0.997 & 0.000 & 0.000 & 0.001 & 0.007 & 0.000 \\
\hline & 2 & 1.812 & 0.000 & 0.986 & 0.592 & 0.000 & 0.000 & 0.002 \\
\hline & 3 & 1.995 & 0.000 & 0.577 & 0.982 & 0.000 & 0.000 & 0.004 \\
\hline & 4 & 2.175 & 0.001 & 0.000 & 0.000 & 1.000 & 0.796 & 0.000 \\
\hline & 5 & 2.431 & 0.008 & 0.000 & 0.000 & 0.796 & 0.999 & 0.000 \\
\hline & 6 & 2.687 & 0.000 & 0.000 & 0.041 & 0.000 & 0.000 & 0.999 \\
\hline
\end{tabular}

(v) Case 5

\begin{tabular}{|c|c|c|c|c|c|c|c|c|}
\hline & \multicolumn{8}{|c|}{ Scenario B } \\
\hline & Mode & & 1 & 2 & 3 & 4 & 5 & 6 \\
\hline \multirow{7}{*}{ 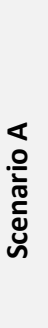 } & & $f(H z)$ & 1.515 & 1.869 & 2.233 & 2.321 & 2.493 & 2.717 \\
\hline & 1 & 1.568 & 0.999 & 0.000 & 0.000 & 0.002 & 0.011 & 0.000 \\
\hline & 2 & 2.101 & 0.000 & 0.996 & 0.594 & 0.000 & 0.000 & 0.010 \\
\hline & 3 & 2.106 & 0.000 & 0.586 & 0.997 & 0.000 & 0.000 & 0.022 \\
\hline & 4 & 2.225 & 0.001 & 0.000 & 0.000 & 0.999 & 0.794 & 0.000 \\
\hline & 5 & 2.481 & 0.008 & 0.000 & 0.000 & 0.796 & 0.999 & 0.000 \\
\hline & 6 & 2.713 & 0.000 & 0.000 & 0.032 & 0.000 & 0.000 & 1.000 \\
\hline
\end{tabular}


(vi) Case 6

\begin{tabular}{|c|c|c|c|c|c|c|c|c|}
\hline & \multicolumn{8}{|c|}{ Scenario B } \\
\hline & Mode & & 1 & 2 & 3 & 4 & 5 & 6 \\
\hline \multirow{7}{*}{ 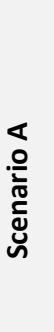 } & & $f(H z)$ & 1.568 & 2.101 & 2.106 & 2.225 & 2.481 & 2.713 \\
\hline & 1 & 1.280 & 1.000 & 0.000 & 0.000 & 0.000 & 0.007 & 0.000 \\
\hline & 2 & 1.812 & 0.000 & 0.996 & 0.601 & 0.000 & 0.000 & 0.002 \\
\hline & 3 & 1.995 & 0.000 & 0.577 & 0.992 & 0.000 & 0.000 & 0.004 \\
\hline & 4 & 2.175 & 0.002 & 0.000 & 0.000 & 1.000 & 0.796 & 0.000 \\
\hline & 5 & 2.431 & 0.011 & 0.000 & 0.000 & 0.795 & 1.000 & 0.000 \\
\hline & 6 & 2.687 & 0.000 & 0.000 & 0.030 & 0.000 & 0.000 & 0.999 \\
\hline
\end{tabular}

